\title{
(C) OPEN ACCESS \\ Combating pancreatic cancer with PI3K pathway inhibitors in the era of personalised medicine
}

\author{
James RW Conway, ${ }^{1}$ David Herrmann, ${ }^{1,2}$ TR Jeffry Evans, ${ }^{3,4}$ Jennifer P Morton, ${ }^{3,4}$ \\ Paul Timpson ${ }^{1,2}$
}

\begin{abstract}
${ }^{1}$ Garvan Institute of Medical Research \& The Kinghorn Cancer Centre, Cancer Division, Sydney, New South Wales, Australia ${ }^{2}$ St Vincent's Clinical School, Faculty of Medicine, University of New South Wales, Sydney, New South Wales, Australia ${ }^{3}$ Cancer Department, Cancer Research UK Beatson Institute, Glasgow, UK

${ }^{4}$ Institute of Cancer Sciences, University of Glasgow, Glasgow, UK
\end{abstract}

\section{Correspondence to} Dr Paul Timpson, Cancer Research Program, Garvan Institute of Medical Research, Darlinghurst, New South Wales 2010, Australia;

p.timpson@garvan.org.au

Received 12 June 2018 Revised 2 October 2018 Accepted 4 October 2018 Published Online First

5 November 2018

\section{Check for updates}

(C) Author(s) (or their employer(s)) 2019. Re-use permitted under CC BY. Published by BMJ.

To cite: Conway JRW, Herrmann D, Evans TRJ, et al. Gut 2019;68:742-758.

\section{ABSTRACT}

Pancreatic ductal adenocarcinoma (PDAC) is among the most deadly solid tumours. This is due to a generally late-stage diagnosis of a primarily treatment-refractory disease. Several large-scale sequencing and mass spectrometry approaches have identified key drivers of this disease and in doing so highlighted the vast heterogeneity of lower frequency mutations that make clinical trials of targeted agents in unselected patients increasingly futile. There is a clear need for improved biomarkers to guide effective targeted therapies, with biomarker-driven clinical trials for personalised medicine becoming increasingly common in several cancers. Interestingly, many of the aberrant signalling pathways in PDAC rely on downstream signal transduction through the mitogen-activated protein kinase and phosphoinositide 3-kinase (PI3K) pathways, which has led to the development of several approaches to target these key regulators, primarily as combination therapies. The following review discusses the trend of PDAC therapy towards molecular subtyping for biomarkerdriven personalised therapies, highlighting the key pathways under investigation and their relationship to the PI3K pathway.

\section{INTRODUCTION}

Accounting for $\sim 95 \%$ of pancreatic cancers, pancreatic ductal adenocarcinoma (PDAC) has a very poor overall 5-year survival of $8 \%$ and is predicted to be the second leading cause of cancer-related deaths in the developed world by $2030 .^{1-3}$ This has only marginally improved since the introduction of gemcitabine in $1995 .{ }^{45}$ Surgery remains the only curative treatment and is often applied with adjuvant chemotherapy, but as few as $10 \%-15 \%$ of patients are eligible at initial diagnosis. $^{6-9}$ Most patients with PDAC have few or non-specific symptoms as the tumour develops, and this means that a large proportion are diagnosed at a late stage, already presenting with locally advanced or metastatic disease. ${ }^{10}$ For those patients that are not immediately eligible for resection, neoadjuvant chemotherapy can be given to reduce borderline tumours prior to resection. ${ }^{11}$ Recent clinical trials aimed at improving response to chemotherapy have demonstrated improved survival with patients treated with either a combination of gemcitabine and nab-paclitaxel or FOLFIRINOX (folinic acid, 5-fluorouracil, irinotecan, and oxaliplatin). ${ }^{12-16}$ However, patient tolerability may be limited with such aggressive treatment regimens. ${ }^{16}$ While improvements in surgical techniques and chemotherapy regimens are providing modest improvements in survival, there is a clear need to better understand this aggressive disease to facilitate both earlier diagnosis and elucidate new targets for combination therapies.

\section{PDAC progression model}

The most widely accepted model for PDAC development is the progression model, in which PDAC originates from preinvasive pancreatic intraepithelial neoplasms (PanINs), which occur in distinct pathological stages, namely PanIN-1A, PanIN-1B, PanIN-2 and PanIN-3. ${ }^{17-19}$ In the early stages (ie, PanIN-1A and PanIN-1B or low-grade), a mucinous epithelium replaces the typically cuboidal morphology of normal pancreatic ducts, with a low level of dysplasia. ${ }^{19-22}$ Yet, recent work has suggested that pancreatic repair after injury, by the process of acinar-to-ductal metaplasia, may also be involved in PDAC initiation. ${ }^{23-25}$ As these PanINs progress (ie, to PanIN-2 and PanIN-3 or intermediate-grade and high-grade, respectively), dysplasia increases and is detectable as nuclear irregularity, loss of cell polarity and an increase in intraluminal apoptotic debris. ${ }^{19-22}$ This progression towards an invasive carcinoma has been shown to occur in parallel with increased proliferation and mutational burden from early preinvasive PanIN stages to metastatic PDAC (figure 1). ${ }^{19} 26$ Importantly, a mechanism underlying the switch from PanIN to metastatic PDAC remains unclear, but new genetically engineered mice that model multistep carcinogenesis may support the widely accepted stepwise mutational model, where some have suggested that catastrophic genomic events may instead trigger the transformation from preneoplastic lesions. ${ }^{27} 28$

A similar progression model has been proposed for intraductal papillary mucinous neoplasms (IPMNs), which are generally benign, but progress to an invasive carcinoma in up to $25 \%$ of cases. ${ }^{29-32}$ Both IPMNs and mucinous cystic neoplasms are radiologically detectable as macroscopic lesions and are classified according to the Sendai guidelines. ${ }^{33}$ They are typically distinguished from PDAC at a macroscopic level by mucoid contents and have distinct stromal subtypes at a microscopic level. ${ }^{34} 35$ Indeed, the mucoid expression itself has been used to subtype IPMNs according to whether the gene expression is gastric or intestinal, which clearly distinguished aggressive disease as the intestinal subtype. $^{35}$

Attempts have been made to classify PanINs in terms of their mutational burden. Initially, evidence 


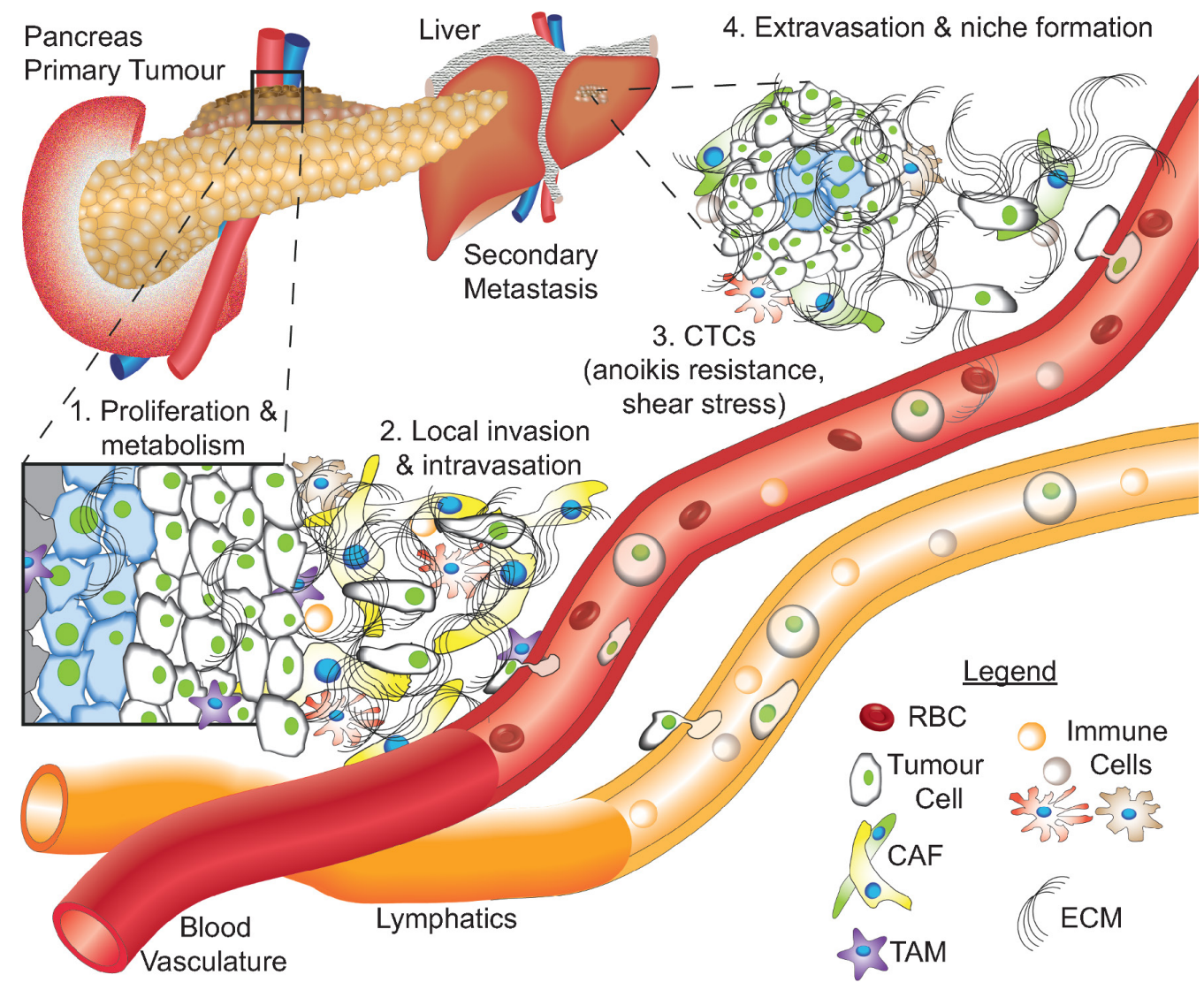

Figure 1 Schematic representation of PDAC progression from the primary tumour to a locally invasive disease and eventually metastasis. (1) Pancreatic cancer cells proliferate in the primary tumour, metabolising nutrients delivered by the blood vasculature and surrounding stroma. (2) Cancer cells invade through the extracellular matrix (ECM), including cancer-associated fibroblasts (CAFs) and tumour-associated macrophages (TAMs), among other cancer-associated cell types, eventually intravasating or invading into the lymph and travelling to distant sites. (3) Circulating tumour cells (CTCS) must develop resistance to anoikis, as well as shear stress, in order to survive in the circulation with red blood cells (RBCs) and leucocytes. (4) After travelling through the circulation, CTCs extravasate at secondary sites, commonly the liver, establishing a new niche. ECM, extracellular matrix; PDAC, pancreatic ductal adenocarcinoma.

of telomere shortening and mutations in KRAS were found to occur very early in PanIN progression. ${ }^{36} 37$ This excluded KRAS as a potential marker for PDAC progression but highlights the general classification as the earliest initiator mutation in PDAC, occurring in $\sim 95 \%$ of PDAC cases. $^{26} 38$ Progression through to PanIN-2 and PanIN-3 typically includes additional mutations in TP53, SMAD4 and/or CDKN2A, but the vast molecular heterogeneity of this disease precludes any single mutation as essential for PDAC development. ${ }^{38} 39$ With this in mind, several large-scale sequencing and mass spectrometry approaches have been implemented to subtype the disease based on these molecular characteristics. ${ }^{40-43}$ The goal of such work is to better integrate biomarkers into the drug discovery pipeline, where lead compound development is performed hand in hand with biomarker identification (figure 2). This parallel preclinical development aims to foster a more personalised approach to clinical trial development, whereby each patient may be assessed for their respective molecular subtype and treatment is designed based on this result (figure 2).

\section{Molecular subtyping of PDAC}

While several mutations occur at relatively high frequency in PDAC, mutations in the aforementioned genes are not currently associated with clinically actionable phenotypes. The milieu of lower frequency mutations, however, has motivated subtyping based on commonly mutated biological processes, termed gene programmes (GPs). The aim of such work is to develop therapeutic strategies that are selectively effective against specific tumour subtypes. ${ }^{1544}$ Early work stratified PDAC according to an activated stromal index, which classified patients according to the ratio of alpha smooth muscle actin (immunohistochemical (IHC) staining) and collagen (stained with the collagen-specific Aniline blue). ${ }^{45}$ Such an index informs primarily on stromal targeting and alone is not sufficient to guide therapies aimed at complete tumour regression. Indeed, a second study took the opposite approach and removed the stroma by laser microdissection from the PDAC samples, prior to microarray analysis and subtyping of PDAC based on multivariate analysis of transcriptional profiles, namely classical, exocrine-like and quasimesenchymal (QM; table 1, see column 'Collisson'). ${ }^{40}$ Such an approach allowed the authors to identify neoplastic epithelial-specific gene expression and to identify pathways involved in PDAC progression. This approach also motivated metabolite profiling within these subtypes, where classical tumours were shown to be lipogenic, while QM tumours were glycolytic. ${ }^{46}$ With clear subtype-specific metabolic targets, new avenues for combination therapies within a personalised setting are an obvious progression to improve patient responses. Additionally, increasing evidence for the importance of the stroma in disease progression means assessment of either the tumour or stroma in isolation is likely to be too simplistic to provide any lasting improvements in patient survival. ${ }^{47}$ 


\section{D and 3D development of lead compounds}

Preclinical testing in GEM or PDX models

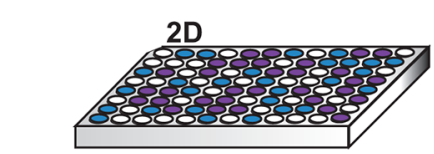

3D

Iteration through late-stage failure or biomarker development.

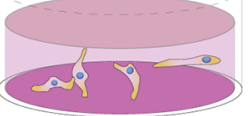

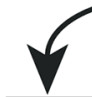

\section{(i) Target} Validation (ii) Lead Identification (iii) Lead Optimization (iv) Preclinical (iv) Preclinica

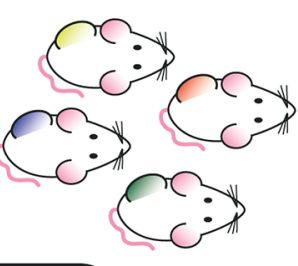

\section{stratification}

Patient

(i-iii) Development of lead compounds for one or more (v) Identify biomarkers or subtypes for later patient stratification

PI3K pathway targets.

(iv) Validate pre-clinical benefit.

(i-iv) Optimize solubility and on-target efficacy. using histopathology, mass spectrometry or genomics approaches.

(vi) Assessment of safety and dosage.

(vii) Personalize treatment based upon biomarker(s) identified in patients that facilitate maximal patient outcome and drug efficacy.

Figure 2 Adaptable drug development pipeline, demonstrating the progression of lead compounds through target validation, lead compound identification and optimisation, then preclinical validation. The necessary addition to this process is the identification of biomarkers to guide both lead compound development and later stratification in phase II/III clinical trials. These processes may be iterated to improve on-target efficacy, solubility and biomarkers. After safety and tolerability is confirmed in phase I clinical trials, biomarker-driven phase II/III may reduce the high attrition rates of lead compounds if appropriate patient stratification can demonstrate beneficial response in the assessed subsets of patients. These biomarkers may also provide opportunities for retrospective analysis and later iteration into clinical trials. PI3K, phosphoinositide 3-kinase.

Physical microdissection approaches rely on IHC to inform stromal activation state and also limit the application of patient subtyping by molecular approaches due to a low sample throughput and smaller sample volume. ${ }^{48}$ As large datasets become increasingly common, new analytical approaches improve the readouts incurred. A more recent approach to PDAC subtyping involved virtual microdissection of large microarray datasets, facilitating molecular subtyping of both the tumour and the stroma. ${ }^{41}$ Using multivariate analysis to distinguish tumour and stromal components, the tumour was split into a classical and more aggressive basal-like subtype, and the stroma was classified into activated or normal subtypes (table 1, see column 'Moffit'). This additional stromal subtyping was

Table 1 Molecular subtyping of patients with pancreatic cancer

\begin{tabular}{|c|c|c|c|}
\hline & Collisson & Moffit & Bailey \\
\hline Approach & Microarray & Microarray & $\begin{array}{l}\text { Expression analysis } \\
\text { (RNAseq and } \\
\text { microarray) }\end{array}$ \\
\hline Cohort & $\begin{array}{l}63 \text { primary } \\
\text { resected PDAC }\end{array}$ & $\begin{array}{l}145 \text { primary resected } \\
\text { and } 61 \text { metastatic } \\
\text { PDAC tumours }\end{array}$ & $\begin{array}{l}96 \text { RNAseq and } \\
242 \text { microarray } \\
\text { primary patient } \\
\text { samples }\end{array}$ \\
\hline $\begin{array}{l}\text { Tumour/stromal } \\
\text { contribution }\end{array}$ & Microdissection & $\begin{array}{l}\text { Multivariate } \\
\text { analysis (virtual } \\
\text { microdissection) }\end{array}$ & Macrodissection \\
\hline \multirow[t]{3}{*}{ Tumour subtypes } & Classical & Classical & $\begin{array}{l}\text { Pancreatic progenitor } \\
\text { Immunogenic }\end{array}$ \\
\hline & Exocrine-like & & ADEX \\
\hline & QM & Basal like & Squamous \\
\hline Stromal subtypes & Not assessed & $\begin{array}{l}\text { Activated } \\
\text { Normal }\end{array}$ & ESTIMATE \\
\hline
\end{tabular}

This pancreatic cancer subtype table is adapted from refs $40-42$. ADEX, Aberrantly Differentiated Endocrine eXocrine; ESTIMATE, Estimation of

STromal and Immune cells in MAlignant Tumor tissues using Expression data; PDAC, pancreatic ductal adenocarcinoma; QM, quasimesenchymal. also recently applied to PDAC patient-derived xenograft (PDX) tumours, whereby tumours classified as basal or classical were shown to have an 'echo' in the mouse stroma. ${ }^{49}$ They further demonstrated the power of their classifications through inhibition of cholesterol uptake in subtyped PDX models, where basal tumours were highly sensitive to inhibition, but classical tumours were shown to have higher NPC1L1 expression and may require a greater concentration of inhibitor to achieve an equivalent growth inhibition.

Further subtyping was recently performed on a 328 primary patient PDAC cohort using expression analysis from RNAseq $(96$ patients) and microarrays (232 patients). ${ }^{42}$ This study included samples with invasive IPMN-associated PDACs and some metastatic tumours and, in contrast to the previous studies, applied macrodissection to excise areas of nonmalignant tissue, maintaining the stromal component in each sample. ${ }^{38} 4250$ Tumour purity could then be inferred in terms of stromal and immune infiltration based on the Estimation of STromal and Immune cells in MAlignant Tumor tissues using Expression data approach. ${ }^{51}$ Beyond purity assessment, this approach facilitated assessment of GPs associated with microenvironmental factors, such as hypoxia, ECM deposition and activated immune pathways. ${ }^{42}$ The microenvironmental influence on cancer progression is an essential consideration for emerging therapies, where immune cells, cancer-associated fibroblasts and ECM components are regularly associated with cancer progression (figure 1). Inclusion of this stromal contribution, as well as the large breadth of patient samples, allowed the authors to reclassify PDAC into four distinct subtypes (summarised in table 1 (see column 'Bailey') and box 1). This is particularly important in light of the high attrition rates for lead compounds currently experienced by the pharmaceutical industry, where more detailed molecular analysis prior to treatment is expected to improve both patient and trial outcomes (figure 2). ${ }^{52-54}$

The goal of this molecular phenotyping is to establish trials, such as IMPaCT, PRECISION-Panc, SHIVA, or biomarker-driven 


\section{Box 1 Pancreatic cancer subtypes}

\section{Molecular subtypes (described in ref ${ }^{42}$ ) Immunogenic}

Patients were classified with this subtype if they showed evidence of high levels of immune infiltrate, which presents an inferred opportunity for emerging immunotherapies.

Pancreatic progenitor

This subtype shares several gene programmes (GPs) with the immunogenic subtype. It is defined by an increased activity of transcriptional networks associated with pancreatic endodermal cell fate. Pancreatic ductal adenocarcinoma (PDAC) associated with IPMN typically fell within this subtype, where an increase in fatty acid metabolism and 0-linked glycosylation of mucins was upregulated.

\section{Aberrantly Differentiated Endocrine eXocrine}

This subtype presented with higher activity of GPs associated with exocrine secretion, consistent with a more differentiated pancreatic lineage.

Squamous

Describing the most aggressive PDAC tumours, including the KPC GEM PDAC model, this subtype is defined by an upregulation of GPs associated with hypoxia, metabolic reprogramming, ECM deposition, squamous differentiation and proliferation.

\section{Neoantigen quality (described in ref ${ }^{280}$ )}

Antigens encoded by tumour-specific genes (neoantigens) are enriched in long-term PDAC survivors, along with high T cell infiltration. The quality of neoantigen may then provide a biomarker for emerging immunotherapies.

\section{Mass spectrometry subtypes (described in ref ${ }^{43}$ ) Using 8 or 33 phosphosites as classifiers, the Australian Pancreatic Cancer Genome Initiative patient-derived cell lines or commercially available pancreatic cancer lines from the American Type Culture Collection were grouped into three subtypes based on their pTyr levels. Of these, subtype 3 in both cell line cohorts was enriched for receptor tyrosine kinase (RTK) phosphorylation and showed increased sensitivity to the epidermal growth factor receptor inhibitor erlotinib. This suggests that mass spectrometry approaches may provide a binary system for classifying patients into RTK or phosphoinositide 3-kinase pathway targeted therapies.}

avatar trials (NCT02795650), where actionable molecular data guides therapies. ${ }^{55} 56$ These trials have established the feasibility of biopsy collection for pancreatic cancer within a clinical setting, where molecular assessment was performed by IHC or genomic approaches. However, biomarker-driven trials for pancreatic cancer remain infrequent, despite increasing evidence for a lack of stratification leading to late-stage failure. This is particularly evident for PI3K pathway inhibitors, where preclinical efficacy is driving their assessment in a clinical setting, but biomarker-driven trials in pancreatic cancer are sorely lacking (table 2). This is in stark contrast to the increase in biomarker-driven trials in other cancers, where biomarkers such as loss of phosphatase and tensin homolog (PTEN), PIK3CA mutation or Akt amplification/mutation are increasingly used to stratify patients for treatment with PI3K pathway inhibitors. ${ }^{57}$ Further to this goal, the subtyping approaches described above may also provide novel clinically actionable biomarkers or GPs to allow patient-selective assessment of PI3K pathway inhibitors to push PDAC survival beyond the current standard of care.

\section{THE PHOSPHOINOSITIDE 3-KINASE (PI3K) PATHWAY}

A broad range of cancer types, including pancreatic cancer, have been candidates for targeting of the PI3K pathway, due to amplification, mutation or loss of key regulators. ${ }^{58} 59$ The PI3K pathway mediates transduction of signals from both extracellular and intracellular sources, including growth factors and nutrients, leading to downstream signalling involved in cancer growth, survival and progression (figure 1). ${ }^{586061}$ The pathway is also essential for many cancer-associated activities, including endothelial cell sprouting for angiogenesis, macrophage transcriptional reprogramming, $\mathrm{T}$ cell differentiation and homeostasis and fibroblast-supported chemoresistance (figure 1). ${ }^{62-65}$ Collectively, this suggests that application of PI3K pathway inhibitors as a PDAC therapy may provide an opportunity for dual targeting of cancer cells and the deregulated cancer-associated stromal components.

PDAC is regularly associated with increased Akt activity, which has been identified in $\sim 60 \%$ of PDAC samples, with amplification of the AKT2 oncogene occurring in $10 \%-20 \%$ of PDAC cases. ${ }^{66-68} \mathrm{Akt}$ is a key effector of the PI3K pathway, downstream of both PI3K and receptor tyrosine kinases (RTKs; table 2). Furthermore, PDAC tumours have been shown to bear an activating mutation in PIK3CA and/or loss of the tumour suppressor PTEN in $\sim 4 \%$ and $25 \%-70 \%$ of cases, respectively. ${ }^{5069-72}$ Interestingly, patients with low PTEN expression have a much higher incidence of recurrence or metastasis, compared with those with high PTEN. ${ }^{72}$ Furthermore, it has been shown that PDAC patients with high PI3K pathway activity show a significantly poorer survival than those with low activation of this pathway. ${ }^{73}$

Several signalling pathways are known to converge on the MAPK and PI3K pathways as effectors of cellular response within the cell. For example, in $\sim 95 \%$ of cases, pancreatic cancer is driven by activating mutations in KRAS, which in turn activates PI3K signalling through the $\mathrm{p} 110 \alpha$ subunit, along with another pathway component PDK1, indicating that a large proportion of patients could benefit from effective targeting of this pathway (figure 3) ${ }^{28}{ }^{73-76}$ Furthermore, detection of mutations in PIK3CA can be predictive for improved patient response in preclinical models of PDAC and in patients with breast cancer stratified according to detection of mutations in circulating cell-free DNA. ${ }^{74}$ 77-79 $^{-}$Given the varied roles of different PI3K isoforms in both the tumour and associated stromal cells, isoform-specific inhibitors provide isolated targeting of oncogenic signalling and allow redundancy to alleviate off-target side effects in healthy tissues (table 2; reviewed in refs 80 81). Notably, a PI3K $\alpha$-specific inhibitor has shown promising efficacy in combination with an EGFRi in PDAC with high EGFR and Akt phosphorylation. ${ }^{82}$ Interestingly, PIK3CA mutations in breast cancer have also been linked with Akt-independent tumour progression through SGK3 and highlight the importance of all levels of this key signalling cascade. ${ }^{83}$ Similarly, isoform-specific PI3K $\beta$ inhibition extended PDAC survival beyond mTORC1/2 targeting alone, ${ }^{84}$ and in other cancers, inhibition of PI3K $\beta$ and PI3K $\delta$ has shown antimetastatic effects and suggests a role of PI3K in tumour metastatic dissemination. ${ }^{85} 86$ Furthermore, isoform-specific inhibition of PI3K $\delta$ in cancer-associated immune cells was shown to downregulate their tolerance to PDAC, which improved the activity of T cells against the cancer. ${ }^{87}$ Collectively, we see strong evidence accumulating for the efficacy of upstream isoform-specific targeting of PI3K in emerging PDAC combination therapies. 
Recent advances in basic science

Table 2 List of PI3K pathway inhibitors currently undergoing clinical development for pancreatic cancer

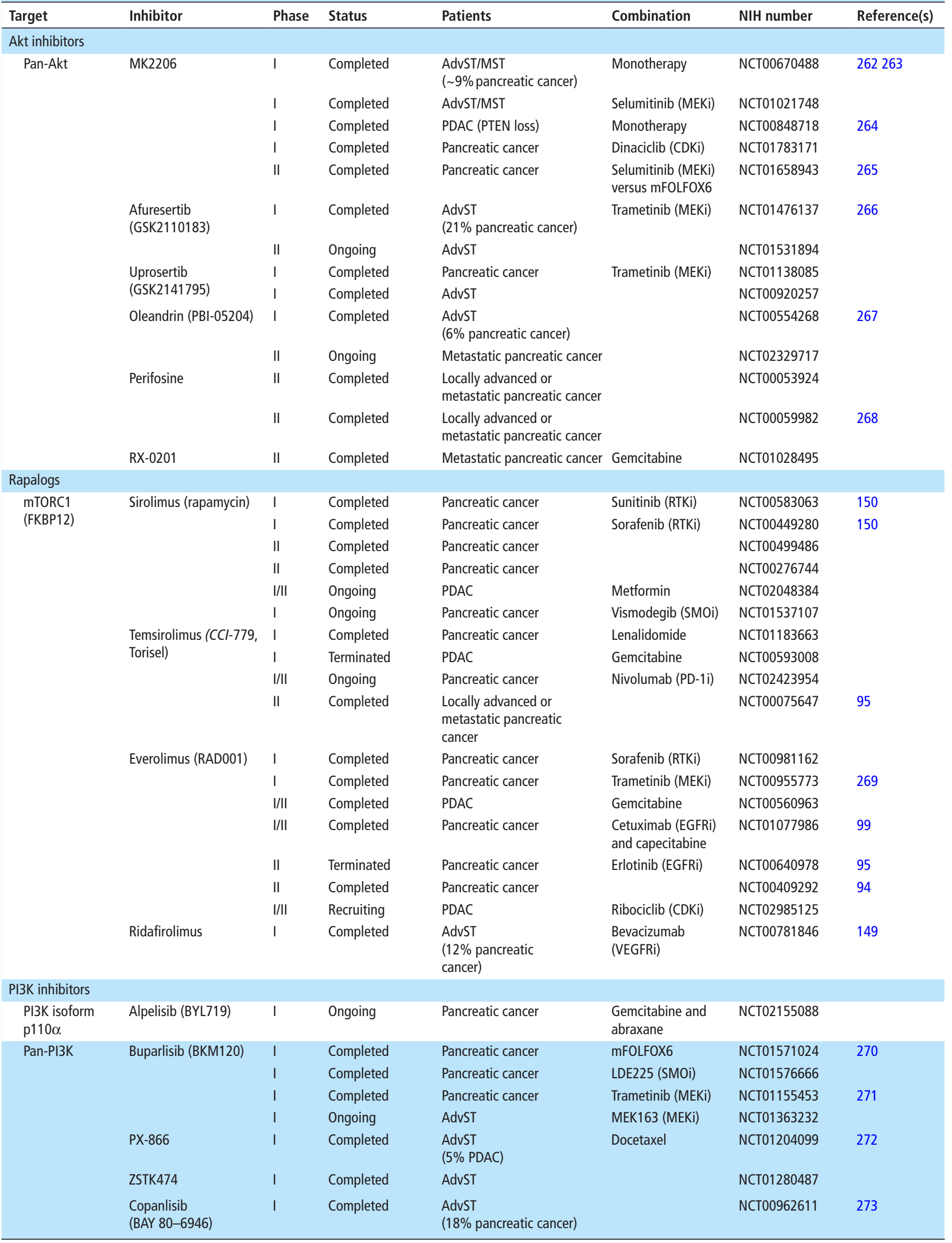




\begin{tabular}{|c|c|c|c|c|c|c|c|}
\hline Target & Inhibitor & Phase & Status & Patients & Combination & NIH number & Reference(s) \\
\hline \multicolumn{8}{|c|}{ Dual PI3K pathway inhibitors } \\
\hline \multirow[t]{5}{*}{ mTORC1/2 } & Vistusertib (AZD2014) & 1 & Completed & AdvST & & NCT01026402 & 98 \\
\hline & & II & Recruiting & AdvST (RICTOR amplified) & & NCT03166904 & \\
\hline & & II & Recruiting & $\begin{array}{l}\text { AdvST: } \\
\text { combination with } \\
\text { Selumitinib (MEKi) }\end{array}$ & & NCT02583542 & \\
\hline & & II & Recruiting & $\begin{array}{l}\text { AdvST (TSC } 1 / 2 \text { loss or } \\
\text { mutation) }\end{array}$ & & NCT03166176 & \\
\hline & & ॥ & Recruiting & $\begin{array}{l}\text { AdvST: } \\
\text { combination with Olaparib } \\
\text { (PARPi) }\end{array}$ & & NCT02576444 & \\
\hline p70-S6K and Akt & LY2780301 & 1 & Complete & $\begin{array}{l}\text { AdvST } \\
\text { ( 22\% pancreatic cancer) }\end{array}$ & & NCT01115751 & 274 \\
\hline \multirow[t]{7}{*}{$\mathrm{PI} 3 \mathrm{~K}$ and $\mathrm{mTOR}$} & $\begin{array}{l}\text { Dactolisib } \\
\text { (NVP-BEZ235) }\end{array}$ & 1 & Completed & AdvST & MEK162 (MEKi) & NCT01337765 & \\
\hline & NVP-BGT226 & 1 & Completed & $\begin{array}{l}\text { AdvST } \\
\text { ( } 2 \% \text { pancreatic cancer) }\end{array}$ & & NCT00600275 & 275 \\
\hline & $\begin{array}{l}\text { Voxtalisib (SAR245409, } \\
\text { XL765) }\end{array}$ & 1 & Completed & $\begin{array}{l}\text { AdvST } \\
\text { ( } 4 \% \text { pancreatic cancer) }\end{array}$ & & NCT00485719 & 276 \\
\hline & $\begin{array}{l}\text { SF1126 } \\
\text { (LY294002 prodrug) }\end{array}$ & 1 & Completed & $\begin{array}{l}\text { AdvST } \\
\text { (5\% pancreatic cancer) }\end{array}$ & & NCT00907205 & 277 \\
\hline & $\begin{array}{l}\text { Gedatolisib (PF- } \\
\text { 05212384, PKI-587) }\end{array}$ & 1 & Terminated & $\begin{array}{l}\text { AdvST } \\
\text { (5\% pancreatic cancer) }\end{array}$ & Irinotecan & NCT01347866 & 278 \\
\hline & & 1 & Completed & $\begin{array}{l}\text { AdvST } \\
(4 \% \text { PDAC) }\end{array}$ & & NCT00940498 & 279 \\
\hline & & 1 & Recruiting & AdvST & Palbociclib (CDKi) & NCT03065062 & \\
\hline
\end{tabular}

AdvST, advanced solid tumours (including pancreatic cancer); CDKi, cyclin-dependent kinase inhibitor; EGFR, epidermal growth factor receptor; EGFRi, EGFR inhibitor; MEKi, MAPK/ERK kinase inhibitor inhibitor; mFOLFOX6, modified FOLFOX (ie, 5-fluorouracil and oxaliplatin); MST, metastatic solid tumours (including pancreatic cancer); mTOR, mechanistic target of rapamycin; NIH, National Institutes of Health; PARP, poly (ADP-ribose) polymerase; PARPi, PARP inhibitors; PDAC, pancreatic ductal adenocarcinoma; PD-1, programmed death-1; PD-1i, PD-1 inhibitor; PI3K, phosphoinositide 3-kinase; RTKi, receptor tyrosine kinase inhibitor; SMOi, smoothened inhibitor; VEGFRi, vascular endothelial growth factor receptor inhibitor.

Concordantly, evidence for the validity of downstream pathway targeting is highlighted in a genetically engineered mouse model of mutant Kras ${ }^{G 12 D}$-driven PDAC, which was applied in concert with a sleeping beauty transposon library, both conditionally expressed (ie, LSL-Kras ${ }^{G 12 D}$ and LSL-SB11) under pancreas-specific Pdx1-Cre. ${ }^{88}$ These approaches identified several genes within the MAPK and PI3K pathways as cooperating mutations for $\mathrm{Kras}^{G 12 D}$-driven PDAC. Similarly, recent assessment of kinases with the highest levels of absolute and differential expression in a panel of pancreatic cancer cell lines demonstrated significantly reduced cell number after knockdown of EGFR, Akt2, PLK2 or MET. ${ }^{90}$ This review will focus on PI3K pathway targeting in PDAC (see also table 2, PI3K pathway inhibitors under clinical investigation in PDAC).

\section{PI3K pathway inhibitors in the clinic}

After the discovery and isolation of rapamycin on the island of Rapa Nui from Streptomyces hygroscopicus, over 30 years of research continues to find new therapeutic applications for this compound..$^{91}$ For example, the mTOR inhibitor (mTORi) rapamycin was recently assessed in PDAC driven by activated PI3K/ AKT signalling via PTEN loss, where targeting of mTORC1 by rapamycin significantly reduced the onset and progression of the disease (figure 3). ${ }^{92}$ Work to improve the solubility and bioavailability of rapamycin-based compounds (rapalogs) has seen modification at the C-42 position through addition of an ester, ether or phosphonate group to generate temsirolimus, everolimus and ridaforolimus, respectively. ${ }^{60}$ Clinical trials in pancreatic neuroendocrine tumours (pNETs) have demonstrated a clear benefit for rapalogs as single agents (table 2) ${ }^{93}$ however, no significant improvements have been identified for rapalogs as single agents in PDAC. ${ }^{94} 95$ This has been attributed to an upstream feedback loop where inhibition of mTORC1 alone relieves the inhibitory phosphorylation of insulin receptor substrate 1 (IRS1)by p70-S6K and mTORC1, leading to an upregulation of Akt phosphorylation (figure 3). ${ }^{9697}$ Hence, while trials of rapalogs may benefit from stratification for patients with high PI3K pathway activity, newer agents that target both mTORC1 and mTORC2, or other pathway components, allow the negation of this feedback loop with promising therapeutic potential (table 2). ${ }^{8498}$ Importantly, new combination therapies with rapalogs should consider the combined toxicity with other targeted compounds. For example, combination of everolimus with the RTKi cetuximab was found to be too toxic for patients with PDAC in a phase I/II clinical trial, while the single agents show minimal toxicity. ${ }^{9499100}$ With this in mind, trials are still ongoing in PDAC using rapalogs in combination therapies (table 2).

Next-generation dual PI3K pathway inhibitors are being developed that take advantage of the homology of the kinase domains from class I, II and III PI3Ks and those of phosphoinositide 3-kinase-related kinases, such as mTOR, ATM and DNA-PK (figure 3, table 2). ${ }^{101}$ However, these dual inhibitors have been linked with drug-related dosage-dependent toxicities, such as hyperglycaemia, nausea, vomiting and diarrhoea, consistent with PI3K isoform targeting, and reinforce the need for preclinical assessment of the additive or synergistic toxicities when 


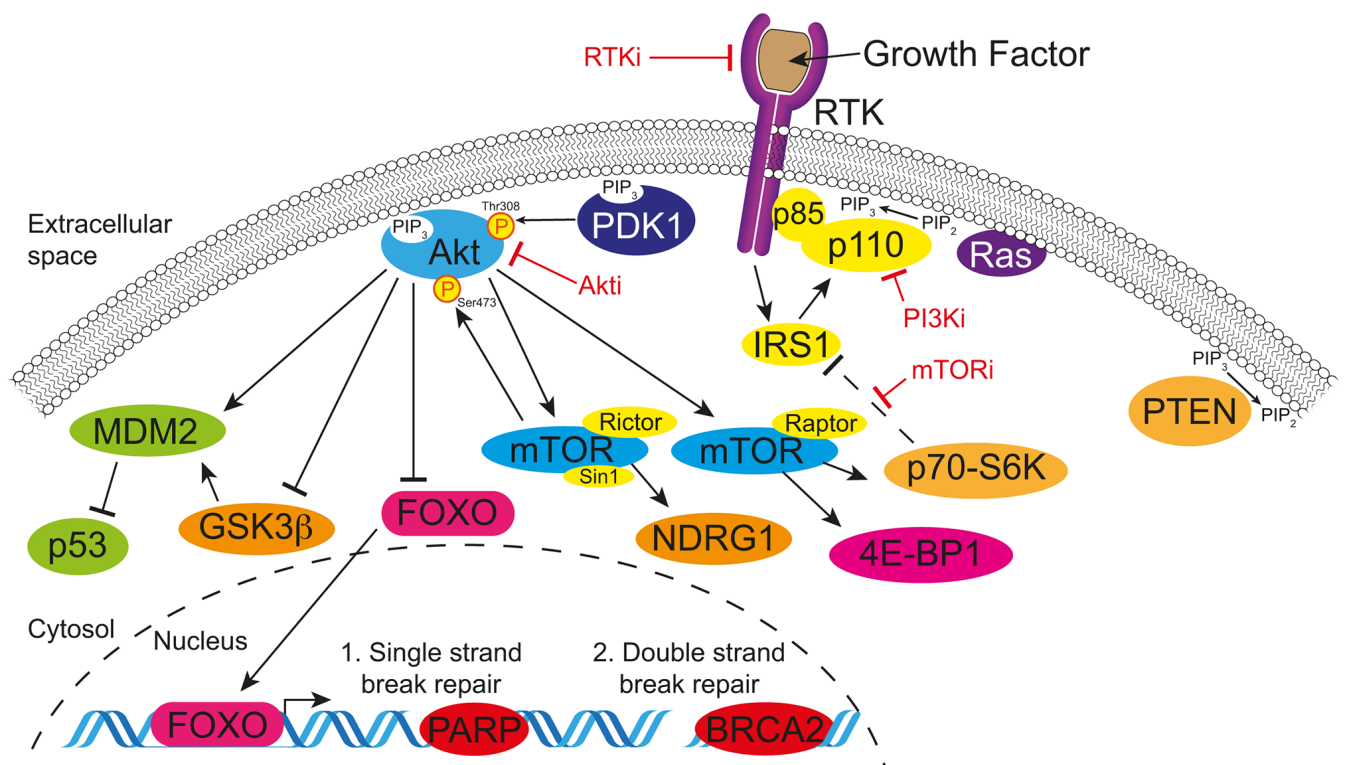

Figure 3 Simplified schematic of the PI3K pathway, which highlights the common targets for small molecule inhibitors. Briefly, signalling from growth factors activates RTKs and recruits PI3K and other scaffold proteins to the cell membrane, where PIP ${ }_{2}$ is converted to PIP. This recruits phosphoinositide-dependent kinase-1 (PDK1) and Akt to the membrane and leads to downstream signalling through the kinase activities of Akt. (1) Single-strand break repair is regulated primarily by PARP and inhibition of PARP can lead to genomic instability. (2) Double-stranded break repair is primarily regulated by a complex with BRCA2, which is lost in familial pancreatic cancer and some PDAC cases and can lead to genomic instability. Genomically unstable tumours require the PI3K pathway to maintain survival pathways and PI3K pathway inhibition may be an emerging option for patients with BRCA2 mutations or in combination with PARP inhibitors. More exhaustive pathway maps can be found in refs 6180 . P13K, phosphoinositide 3-kinase; RTKs, receptor tyrosine kinases.

developing novel combination therapies. ${ }^{81}$ Moving forward, improvements in solubility are driving greater oral bioavailability, where lower drug dosages can show equivalent drug efficacy and gastrointestinal toxicities are readily reduced. ${ }^{102} 103$ One exciting example of a dual PI3K pathway inhibitor is AZD2014, which was developed by iterative structure-activity relationship medicinal chemistry approaches to have high aqueous solubility and a potent inhibitory effect against both mTORC1 and mTORC2. ${ }^{104}$ Recent preclinical work by our group has demonstrated potent antiproliferative and anti-invasive effects in the KPC (LSL-Kras ${ }^{G 12 D}, L S L-T r p 53^{R 172 H}$ and Pdx1-Cre) GEM PDAC model ${ }^{84105}$ and after a promising phase I clinical trial in advanced solid tumours (AdvSTs), AZD2014 has progressed to phase II biomarker-driven clinical trials either alone or in combination with a MAPK/ERK kinase inhibitor (MEKi) (table 2). ${ }^{98}$ The additional anti-invasive role for AZD2014 is consistent with increasing evidence for the emerging antimetastatic and anti-invasive effect of PI3K pathway targeting (figure 1). ${ }^{105-109}$ Indeed, the opposing roles for the different Akt isoforms in cell motility have identified an invasion and metastasis promoting role of Akt 2 but an inhibitory role for Akt1. ${ }^{110-114}$ The dual role of Akt1 in either promoting tumour growth or metastasis was recently shown to be regulated by the inositol polyphosphate 5 -phosphatase (PIPP), where PIPP ablation resulted in reduced metastasis but increased tumour growth. ${ }^{108}$ Similarly, mTORC1 and mTORC 2 have been shown to regulate migration and invasion through Rac1 and RhoA. ${ }^{58} 80115$ Furthermore, mTOR inhibition dramatically reduced metastasis in prostate cancer, highlighting the broader potential of PI3K pathway therapeutics as antimetastatic agents. ${ }^{116}$ Intriguingly, the mTOR inhibitor, everolimus, resulted in a partial response in a patient with pancreatic cancer that was induced by Peutz-Jeghers syndrome (PJS). ${ }^{117}$ PJS is caused by a tumour-suppressor gene mutation in the serine threonine kinase 11 gene (STK11, also known as
LKB1), which results in $\sim 11 \%-36 \%$ of patients with PJS developing pancreatic cancer. ${ }^{117}$ This loss of STK11 leads to a loss of suppression of mTOR signalling and raises the tantalising possibility that mTOR inhibition could have monotherapy efficacy in PDAC in selected cases with a similar genetic background.

\section{EMERGING OPPORTUNITIES FOR COMBINATION THERAPIES} Opportunities for patients with RTK amplification or mutation The RTK family comprises several subfamilies that are not limited to ErbB, fibroblast growth factor receptors (FGFRs), insulin and insulin-like growth factor receptors, platelet-derived growth factor receptor (PDGFR), vascular endothelial growth factor (VEGF) receptor (VEGFR) and Axl and the Ephrin receptors. Inhibition of these receptors using RTK inhibitors (RTKi) generally takes one of three forms: antibody or recombinant protein inhibition of the extracellular ligand binding domain, inhibition of the ligand itself, or targeting of the cytoplasmic tyrosine kinase domain.

In recent work, 19 PDAC cell lines from the American Type Culture Collection and 17 patient-derived cell lines (PDCLs) from the Australian Pancreatic Cancer Genome Initiative collection, sequenced as part of the International Cancer Genome Consortium (ICGC), were used to assess global phosphotyrosine (pTyr) profiles in PDAC by mass spectrometry. ${ }^{43}$ This approach allowed the authors to define two sets of classifier mutations ( 8 and 33 pTyr sites) that predicted three PDAC subtypes over the two cell line panels (box 1). Interestingly, when RTK activity was enriched, the cell lines showed an enhanced sensitivity to the EGFRi erlotinib, suggesting that this subtyping approach may provide a method to stratify patients for RTK-targeted therapies. While the somatic mutation profiles did not correlate with the pTyr-based subtyping, similar GPs were identified between both the genomic and mass spectrometry studies. ${ }^{4243}$ However, at the 
mass spectrometry level, it was possible to identify the activation status of kinase networks and receptors. This lends weight to the overlapping use of both genomic and mass spectrometry approaches to assess aberrant pathway expression, mutation status and, importantly, activation state and provides clear motivation for the incorporation of both techniques into the drug discovery pipeline (figure 2).

\section{The ErbB family}

RTKs are transmembrane receptors that communicate signals from ligands outside of the cell by activating their cytoplasmic tyrosine kinase domains, which facilitate downstream signalling within the cell, typically through activation of the MAPK and PI3K pathways. The ErbB family contains four RTKs structurally related to the epidermal growth factor receptor (EGFR; human epidermal growth factor receptor (HER) 1 and ErbB-1). EGFR expression is observed in normal pancreatic ducts but has been shown to increase from the early stages of PanIN development through to PDAC. ${ }^{118-120}$ Targeting of the EGFR receptor with the small molecule inhibitor erlotinib in combination with gemcitabine resulted in a statistically significant, but clinically modest, improvement in overall survival compared with gemcitabine monotherapy in patients with metastatic disease and has also been evaluated in the adjuvant setting. ${ }^{121} 122$ These studies subsequently motivated the assessment of predictive markers that would stratify patients for this treatment. ${ }^{123-126}$ These studies found conflicting evidence for KRAS mutational status as a predictive or prognostic marker for erlotinib response but suggested that mutations or amplification of EGFR may be sufficient to stratify patients for therapy. Interestingly, expression of ErbB-3 (HER3) has been associated with sensitivity to erlotinib treatment in pancreatic cancer cell lines and therefore may prove an effective biomarker for adjuvant erlotinib for patients with PDAC. ${ }^{127-129}$ ErbB-3 requires heterodimerisation for downstream signalling through the PI3K pathway and expression in PDAC is a poor prognostic factor for survival. ${ }^{127-129}$ Another emerging personalised approach to PDAC therapy comes from the success of targeting ErbB-2 (neu and HER2) amplified tumours with a humanised monoclonal antibody. ${ }^{130}$ ErbB-2 amplification in PDAC has a relatively low prevalence of $2 \% ;^{50131} 132$ however, clinical trials with trastuzumab (Herceptin) in combination with chemotherapy have shown beneficial responses in metastatic PDAC patients with ErbB-2 amplification, ${ }^{133} 134$ and studies are still ongoing in metastatic or recurrent PDAC. ${ }^{56}$ ErbB-4 (HER4) is the last member of the ErbB family but is only weakly expressed in PDAC. ${ }^{135136}$ However, given the established importance of the other ErbB family members in PDAC progression, they may also prove effective biomarkers for inhibition of the PI3K pathway, which is less sensitive to changes in receptor dimerisation.

FGFR, PDGFR and VEGFR stromal targeted therapies and biomarkers The FGFR, PDGFR and VEGFR families share sufficient structural homology that targeting of these receptors often has overlapping responses. In PDAC, overactivation of FGFR signalling has been associated with $2 \%$ of patients, and targeting of this receptor in PDAC using dovitinib has recently completed a phase I clinical trial in combination with chemotherapy, after a promising preclinical study, where dovitinib was found to exert its effect through decreased Akt activity (NCT01497392). ${ }^{50} 137$ Furthermore, FGFR and PDGFR upregulation in a proof-of-principle study using Kras-deficient PDAC was recently linked with increased sensitivity to PI3K pathway targeting highlighting the essential supportive role this pathway plays in PDAC progression and the potential of RTKs as biomarkers for patient stratification. ${ }^{138}$ Interestingly, inhibition of FGFR alone or in combination with PDGFR inhibition was not sufficient to decrease cancer cell proliferation to the same degree as PI3K pathway inhibitors, indicating that multiple RTK pathways feed into PI3K activation in PDAC and that PI3K inhibition may provide an opportunity for targeting of multiple de-regulated RTK pathways simultaneously (figure 3). ${ }^{138}$

Due to the highly desmoplastic reaction characteristic of PDAC, it is important to consider the stromal responses to therapies and even look for new targets within this compartment. Moreover, the effect of FGFR targeting in stromal pancreatic stellate cells has also demonstrated a beneficial outcome by reducing cancer cell invasion and hence better containing the tumour. ${ }^{139}$ This suggests that PI3K pathway inhibition may also have an antistromal effect that reduces the protumourigenic role of the activated cancer-associated fibroblasts and stellate cells, but as yet, this effect has not been assessed. Interestingly, overexpression of FGFR has also been used in a less conventional approach, where targeting this cell-surface receptor with an antibody-conjugated adenovirus specifically delivered a viral gene. ${ }^{140}$ This viral gene then predisposed these cells to antiviral therapy by ganciclovir. While this work has not progressed beyond preclinical models, other alternative therapies, such as antibody-conjugated nanoparticles, toxins, viruses or CAR-Ts,${ }^{141-144}$ highlight the variety of emerging therapies that could potentially combat this primarily treatment-refractory disease.

PDGFR is less commonly mutated in PDAC, but upregulation of PDGFR signalling has been implicated as a mechanism for metastatic progression in p53-mutated tumours. ${ }^{42} 145{ }^{146}$ Interestingly, one patient with PDAC who responded well to AZD2014 therapy in a phase I trial was found to have a PDGFR1A mutation, and this may present a novel biomarker for therapies aimed at PI3K pathway inhibition. ${ }^{98}$ An important function of PDGFR signalling is an overlapping role with VEGFR signalling for angiogenesis, which has been extensively assessed as a target in PDAC. ${ }^{147}$ After promising clinical trials led to approval of the mTORC1 inhibitor rapamycin and the broad-spectrum RTKi Sunitinib in pNETs, which are typically highly vascularised, several clinical trials began looking at the effectiveness of these inhibitors in PDAC (table 2). ${ }^{93} 148$ However, the antiangiogenic effects in PDAC provided minimal clinical benefit and future clinical trials are looking at the application of RTKi as part of combination therapies (table 2). ${ }^{149-152}$ One interesting target that has emerged from VEGFR targeting strategies is the discovery that placental growth factor, a VEGF homologue, is specifically upregulated in tumour vasculature and provides a target for disease-specific angiogenesis, without affecting normal healthy vessels. ${ }^{153}$ However, the effectiveness of this strategy remains controversial and has yet to progress to the clinic. ${ }^{154}$

\section{Ephrin receptors as predictive biomarkers or novel targets}

The largest known RTK family is that of the Ephrin receptors, of which both the EphrinA and EphrinB subfamilies are associated with poorer survival in patients with PDAC and are predictive of tumour proliferative and growth capacity. ${ }^{155}{ }^{156}$ Indeed, increased activity of EphrinA2 has been associated with Krasdriven PDAC progression and knockdown in a mouse model of PDAC decreased metastasis. ${ }^{43} 157$ Furthermore, axon guidance GPs in which EphrinA5 and EphrinA7 play a role have been implicated in PDAC development, providing further motivation for application of the EphrinA/EphrinB receptors as predictive 
biomarkers for aggressive disease. ${ }^{38}$ Their continued association with PDAC has led to several approaches to therapeutically target these receptors. ${ }^{158}$ For example, a recent toxin-conjugated monoclonal antibody against the EphrinA2 receptor MEDI547 completed phase I clinical trials in treatment-refractory solid tumours. ${ }^{159}$ Similarly, the broad-spectrum small molecule tyrosine kinase inhibitor dasatinib has an established inhibitory effect on the intracellular kinase domains of Ephrin receptors and provides a parallel approach for targeting of other RTKs. ${ }^{160}$ After promising preclinical studies, dasatinib has progressed to clinical trials for metastatic PDAC in combination with FOLFOX (NCT01652976) or gemcitabine/erlotinib (NCT01660971) chemotherapy. ${ }^{161-163}$ However, dasatinib in combination with gemcitabine did not improve overall compared with gemcitabine and placebo in locally advanced, non-metastatic PDAC. ${ }^{164}$ Another common approach to target upregulated Ephrin signalling is to inhibit the downstream pathways, such as the MAPK or PI3K pathways. ${ }^{158}$ Importantly, as PDAC therapy necessarily turns towards predictive biomarkers to guide personalised therapies, upregulation of Ephrin family members may predict response to RTK, MAPK or PI3K pathway inhibition in PDAC.

\section{Canonical and non-canonical inhibition of aberrant transforming growth factor $\beta$ (TGF $\beta$ ) signalling}

The membrane-bound TGF $\beta$ receptor is mutated at a relatively low frequency in PDAC. ${ }^{50}$ However, disruptions in other pathway components occur in $\sim 47 \%$ of patients, including mutations in SMAD4, SMAD3, TGFBR1, TFGBR2, ACVR1B and $A C V R 2 A .{ }^{42}$ There is a complex relationship between TGF $\beta$ signalling and either tumour suppression or metastatic spread. ${ }^{165}$ Indeed, loss of SMAD4 is indicative of a poorer prognosis, while TGF $\beta$ pathway activation is associated with an epithelial-to-mesenchymal transition, one of the driving factors for metastatic dissemination. ${ }^{165} 166$ This has made TGF $\beta$ signalling the focus of recent clinical trials combining TGF $\beta$ receptor inhibition with gemcitabine (NCT02154646 and NCT01373164) or immunotherapy (NCT02734160). However, these trials are not biomarker driven and hence are not stratified for SMAD4 mutational status, which is associated with failure of adjuvant chemotherapies in PDAC. ${ }^{167168}$ The role of SMAD4 in TGF $\beta$ signalling is primarily tumour suppressive, and this function may limit application of TGF $\beta$ receptor inhibitors, where they would best be applied to patients with SMAD4 deletion. ${ }^{169}$ A key non-canonical mediator of TGF $\beta$ signalling is the PI3K pathway, which was shown to be inhibited by TGF $\beta$ receptor inhibitors and activated by endogenous TGF $\beta .{ }^{165} 170{ }^{171}$ Hence, an alternative route, independent of the tumour-suppressive functions of TGF $\beta$ signalling, may be through inhibition of these non-canonical signalling pathways.

\section{Targeting DNA damage repair defective tumours}

Aberration in DNA damage repair pathways, such as mutations in BRCA1, BRCA2, PALB2 or ATM, are commonly associated with increased risk of familial pancreatic cancer, ${ }^{172}{ }^{173}$ but also occur in the later stages of PanIN development and PDAC. ${ }^{18} 204256$ Loss of these DNA repair proteins leads to genomic instability and predisposes patients to breast, ovarian, prostate and pancreatic cancers. ${ }^{174-176}$ Patients with mutations in this pathway in other cancers have shown beneficial responses to PARPi, and recent clinical trials in PDAC have been performed to assess the beneficial role of second-line olaparib monotherapy in BRCA1/2-deficient patients, following failure on gemcitabine. ${ }^{177}$ PARPi work on the basis of synthetic lethality whereby tumours with defects in double-stranded DNA repair pathways become dependent on PARP to repair the resultant collapsed replication forks and maintain chromosomal stability and cell cycle progression. ${ }^{178-180}$ Another option for patients with mutations in DNA repair pathways is by causing further DNA damage in these defective cells by either platinum-based therapies or mitomycin C. ${ }^{56181}$ Furthermore, the PI3K pathway has a well-established role in DNA damage repair, and promising combination therapies in endometrial and breast cancers have motivated clinical trials in PDAC to assess the effect of PARPi in combination with PI3K pathway inhibitors (table 2, figure 3). ${ }^{182-184}$ The clear responses seen in patients presenting with these DNA repair defects provides a promising personalised approach to therapy when standard of care is found to be ineffective.

\section{Sensitisation of cell cycle defective tumours to cyclin- dependent kinase (CDK) inhibitors as combination therapy} Mutations in CDKN2A, CCND1 and/or CDK4/6 commonly occur in PDAC, and recent work has demonstrated that the reliance of some tumours on this pathway may sensitise them to $\mathrm{CDK}$ inhibitors (CDKi). ${ }^{50}$ In recent work, the sensitivity of a panel of PDCLs was assessed for their response to a CDKi, which identified PDCLs with high expression of retinoblastoma protein and low expression of $\mathrm{p} 16^{\mathrm{INK} 4 \mathrm{~A}}$ were significantly correlated with improved response to CDKi, in combination with gemcitabine. ${ }^{185}$ This is in line with work in breast and ovarian cancers, and melanoma, where this same expression pattern is common. ${ }^{186-188}$ Furthermore, it has been shown that in PDAC and other cancers, combinations of CDKi with PI3K pathway inhibition in subsets of patients can have an even greater response, thus stratification in this setting may warrant further investigation (table 2). ${ }^{189} 190$

\section{Histone deacetylases (HDACs) and mutant p53 inhibitors}

Loss or mutation of the tumour suppressor p53 occurs in $\sim 75 \%$ of patients with PDAC, where gain-of-function mutations occur at a higher prevalence and are thought to provide a growth advantage, as well as driving metastatic progression. ${ }^{50191192}$ The primary role of p53 is to bind DNA as a transcriptional activator or repressor, mediating transcriptional networks responsible for cell death and replicative senescence in response to genotoxic or oncogenic stress. ${ }^{193} 194$ HDACs work by regulating gene expression at an epigenetic level and have been associated with upregulation of mutant p53 in several cancers, including PDAC. ${ }^{195}{ }^{196}$ Furthermore, several HDACs are overexpressed in PDAC, prompting assessment of the clinical benefit of their inhibition. ${ }^{197} 198$ Recently, a phase I clinical trial of vorinostat with chemoradiation in PDAC showed promising overall survival benefits. ${ }^{199}$ In parallel, emerging studies in other AdvSTs demonstrated promising synergistic benefits when combining vorinostat with the broad-spectrum RTKi sorafenib ${ }^{200201}$ and subsequently led to a new phase I trial of vorinostat and sorafenib with chemotherapy in PDAC (NCT02349867).

One of the key mediators of p53 protein stability is mouse double minute 2 (MDM2), which is responsible for ubiquitination and subsequent degradation of $\mathrm{p} 53$ by the proteasome. ${ }^{202}$ Mutation of CDKN2A occurs in 35\% of PDAC tumours leading to loss of expression of the tumour suppressors $\mathrm{p} 16^{\mathrm{INK} 4 \mathrm{a}}$ and $\mathrm{p} 14^{\mathrm{ARF}}$ (p19 ${ }^{\mathrm{ARF}}$ in murine tumours). ${ }^{50} \mathrm{ARF}$ inhibits MDM2, and hence loss of this tumour suppressor leads to increased levels of MDM2 and a decrease in p53 pathway activity. ${ }^{203}$ Another key mediator of MDM2 activation is Akt, which activates MDM2 in parallel with other survival pathways (figure 3). ${ }^{61}$ 
Furthermore, the tumour suppressor PTEN has been shown to bypass MDM2 and stabilise $\mathrm{p} 53$ protein levels, leading to downstream activity. ${ }^{204} 205$ In the complex mutational landscape of PDAC, it is unclear how PI3K pathway inhibitors may affect the already overexpressed levels of mutant p53. ${ }^{206}$ However, 26\% of PDAC tumours retain wild-type $\mathrm{p} 53$, and recent work demonstrated that MDM2 inhibitors were able to reactivate wild-type p53 pathway signalling in pancreatic cancer. ${ }^{207}$ This may suggest that PI3K pathway inhibition in PDAC could reduce MDM2 levels and facilitate activation of the tumour-suppressive functions of p53 and lead to apoptosis. ${ }^{208}{ }^{209}$ Caution may need to be taken however, for patients with p53 mutations where upregulation of this mutant protein may enhance tumourigenesis. ${ }^{210}$ The complex relationship between these pathways includes GSK-3 $\beta$, which has been implicated in MDM2 activation and p53 degradation. ${ }^{211} 212$ GSK-3 $\beta$ is a canonical Akt substrate and is inactivated by this phosphorylation interaction (figure 3). ${ }^{61}$ This complex regulation of MDM2 by different members of the PI3K pathway may explain the complex responses of $\mathrm{p} 53$ wild-type or deficient tumours when applying PI3K pathway inhibitors as radiosensitising agents. ${ }^{213-216}$

\section{Development of small molecule inhibitors for oncogenic KRAS and MAPK signalling}

Mutations in KRAS occur in $~ 95 \%$ of PDAC cases, and this has prompted several efforts to target both mutant KRAS and the resultant aberrant downstream signalling. ${ }^{26}{ }^{38}$ The predominant KRAS mutations in PDAC are KRAS ${ }^{G 12 D}$ and KRAS ${ }^{G 12 V}$, where KRAS ${ }^{G 12 D}$ accounts for $83 \%$ of KRAS mutations in PDAC and has been shown to classify into more aggressive molecular subtypes. ${ }^{41} 217$ This aggressive classification may be due to the downstream signalling cascades that have been linked to specific KRAS mutants, where $K R A S^{G 12 D}$ predominantly activates the MAPK and PI3K pathways, whereas $K R A S^{G 12 V}$ predominantly activates Ral signalling. ${ }^{218}$ Several attempts have been made to inhibit oncogenic Ras isoforms by either competitive inhibition of GTP binding or by preventing membrane translocation but have so far failed to successfully inhibit Ras at a low enough dose for clinical efficacy. ${ }^{217}$ Similarly, the farnesyl transferase inhibitor, tipifarnib, did not prolong overall survival compared with gemcitabine alone in advanced PDAC. ${ }^{219}$ Interestingly, RNA interference approaches have been efficaciously applied to PDAC tumours that were metabolically reprogrammed by mutant Ras, where inhibition of the mutant isoform was sufficient to delay tumour growth. ${ }^{220-222}$ With this in mind and by successfully delivering small inhibitory RNAs (siRNAs), one group was able to demonstrate the in vivo application of a miniature biodegradable polymeric matrix for delivery of a $K R A S^{G 12 D}$-targeted siRNA. ${ }^{221}$ Knockdown of oncogenic KRAS ${ }^{G 12 D}$ at the transcript level effectively inhibited downstream pathways and reduced in vivo tumour burden. Another recent approach to deliver siRNAs against oncogenic $K R A S^{G 12 D}$ to PDAC tumours is using fibroblast-derived exosomes, termed iExosomes, which maintain CD47 expression and hence show increased bioavailability and tumour uptake. $^{220}$

As an alternative approach to inhibition of oncogenic KRAS, innumerable inhibitors have been developed to target the key signalling cascades immediately downstream, namely the MAPK and PI3K pathways. Several clinical trials have been performed using MEKi in combination with gemcitabine, ${ }^{223} 224$ but these have so far failed to demonstrate significant improvements in survival, compared with gemcitabine alone. Inhibition of the MAPK pathway is regularly associated with an increase in PI3K pathway activity. ${ }^{225} 226$ Hence, new treatment strategies have emerged that aim at inhibiting both of these key effector pathways (table 2). While these follow from promising preclinical studies, where the combined efficacy of dual MAPK and PI3K pathway inhibition provides significant tumour growth inhibition, the combined toxicity of this approach can present a strong limiting factor. ${ }^{226} 227$ Notably, the sequential effect of targeting these pathways may increase tumour susceptibility to inhibition while potentially minimising toxicity. ${ }^{228}$

\section{MICROENVIRONMENTAL INFLUENCES ON DRUG RESPONSE}

PDAC is characterised by a highly desmoplastic reaction, commonly associated with high levels of stromal infiltration, ECM deposition and tumour hypoxia. ${ }^{47} 229$ Targeting of the ECM or associated stroma has shown some efficacy in PDAC, by improving drug delivery and sensitising tumours to chemotherapy, ${ }^{230-232}$ although the viability of targeting the stroma in PDAC remains controversial. Complete stromal ablation in PDAC was shown to enhance cancer aggressiveness, ${ }^{233} 234$ which calls for more subtle and targeted approaches to normalising instead of completely ablating the tumour-associated stroma. ${ }^{47235}$ This effect is partly thought to occur due to a normalisation of the tumour vascular network and manipulation of the ECM/ stroma, improving drug efficacy in the tumour. ${ }^{231} 235236$ Another common feature resultant from enhanced desmoplasia is the development of a hypoxic environment (figure 4). Hypoxia is strongly associated with increased radioresistance, chemoresistance and metastasis, ${ }^{237-239}$ and PDAC is among those cancers with a propensity for high levels of tumour hypoxia, which is predictive of poorer patient prognosis. ${ }^{229} 240$

Reduced oxygen consumption and increased glycolysis were recently identified by mitochondrial genome sequencing in PDAC PDCLs. ${ }^{241}$ This is a key aspect of the Warburg effect, which predicts tumours to rely more heavily on glycolysis for their metabolism. ${ }^{242}$ While this presents an advantage for tumours that experience reduced vascularity and oxygen levels, it also presents an opportunity to potentially starve the tumour in these hypoxic regions. ${ }^{243}$ One of the first steps for tumours to switch to glycolytic metabolism is an increase in lactate dehydrogenase (LDH) activity, which converts pyruvate into lactate. ${ }^{244}$ Inhibition of LDH has recently been shown to synergise with gemcitabine in vitro and may provide a novel strategy for PDAC. ${ }^{245}$ Another important aspect of PDAC metabolism is the metabolic reprogramming resultant from KRAS mutation, which upregulates glucose uptake and biomass synthesis. ${ }^{246}$ Furthermore, the upregulation of MUC1 during PDAC progression, along with HIF1 $\alpha$ in hypoxic tumour regions, has been shown to cooperate by upregulating anabolic metabolism through the pentose phosphate pathway, resulting in gemcitabine resistance. ${ }^{247}$ The glycolytic switch in hypoxia can lead to a decrease in $\mathrm{pH}$, and hence $\mathrm{pH}$-regulating proteins are also an important downstream target of the cellular hypoxic response. ${ }^{248}$ Inhibitors of these $\mathrm{pH}$-regulatory components are currently being assessed, after promising preclinical work, for their role in limiting tumour growth. ${ }^{249} 250$ The PI3K pathway also plays an important role in glucose uptake, amino acid metabolism and response to cellular stress. ${ }^{58} 6061$ In hypoxia, Akt activity is upregulated, along with glucose transporters, to facilitate the switch to anaerobic metabolism. ${ }^{105} 214238243$ Moreover, treatment of PDAC with PI3K pathway inhibitors is less effective in hypoxia, highlighting an important microenvironmental consideration for future stratified clinical trials. ${ }^{105} 251$

With this in mind, we recently demonstrated that a hypoxia-activated prodrug (HAP) could alleviate hypoxia-induced resistance to a PI3K pathway inhibitor in a combination 


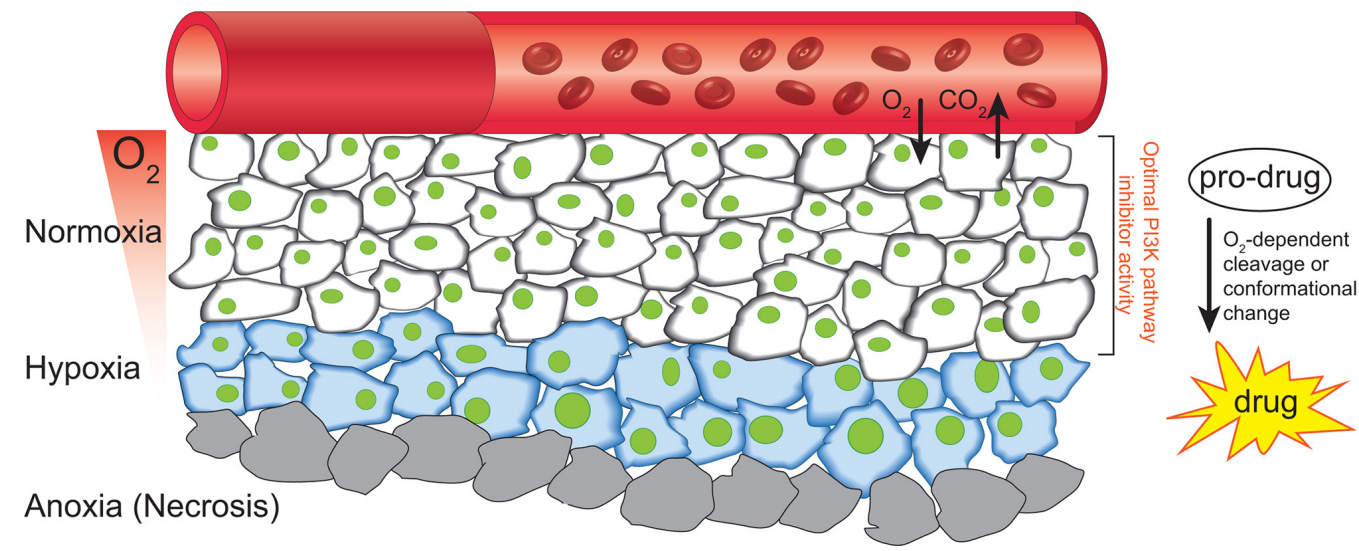

Figure 4 Schematic of the formation of a hypoxic environment and the potential targeting of this microenvironment with HAPs. RBCs transport oxygen through the blood vasculature, and hypoxia forms when this diffusion-limited process delivers insufficient oxygen to cells distant to the vasculature (blue cells). The extreme case of anoxia (grey cells) regularly results in necrotic cell death. HAPs take advantage of the hypoxic environment of tumours to deliver cytotoxic compounds to these tumour regions, where the prodrug is either enzymatically cleaved by the cells metabolic machinery or undergoes a conformational change in response to the low oxygen partial pressure. HAPs, hypoxia-activated prodrugs; RBCs, red blood cells.

therapy. ${ }^{105}$ HAPs are typically metabolised by enzymatic reduction in hypoxia from a primarily inactive form to an active form while having limited effects on normoxic or healthy tissues, making them ideal for development of combination therapies (figure 4; reviewed in ref 238). This approach was also found to be effective in renal cell carcinoma, where combination with rapalogs and the HAP TH-302 significantly improved survival in preclinical models. ${ }^{252}$ The efficacy of these HAPs began to be realised with tirapazamine, which showed a high differential toxicity in hypoxia, compared with normoxia, which made it an ideal candidate for combination with radiotherapy. ${ }^{253} 254$ However, despite promising phase II clinical trials in squamous cell carcinoma, a phase III trial failed to show improved efficacy over chemoradiotherapy alone. ${ }^{255}$ Notably, this trial was not biomarker driven and hence did not stratify patients based on hypoxic tumour burden, which may have disguised any potential efficacy in a subset of patients. This is a common issue in clinical trials and is also implicated in the phase III failure of TH-302 after promising phase II results (NCT01746979). ${ }^{256}$ The preclinical promise and potential applications of HAPs in combination therapies means that despite the phase III setbacks, improved tirapazamine analogues, such as SN3000 and SN29751, as well as other recently developed HAPs, including PR-104 and AQ4N, are all under preclinical/clinical investigation. ${ }^{257-259}$

Recent work by our group demonstrated that a hypoxic gene signature was associated with a poorer prognosis for patients with PDAC. ${ }^{229}$ While this is a promising approach, application in the clinic may be limited by the collection of patient biopsies, which may not adequately represent the extent of hypoxia within the whole tumour. The necessary stratification of patients for future clinical trials calls for a method to assess the whole tumour non-invasively (figure 2). To this end, positron emission tomography approaches have been developed based on radiolabelled 2-nitroimidazoles or antibodies, which can be coupled with ${ }^{18} \mathrm{~F}$-fluorodeoxyglucose imaging to first identify malignant lesions. ${ }^{238}$ Similarly, non-invasive imaging of oxygen partial pressure using electron paramagnetic resonance imaging or assessment of pyruvate metabolism by MRI have also been used to stratify PDAC tumours for treatment with TH-302 and radiation. ${ }^{260}$

Moving forward, the design and synthesis of HAPs with defined molecular targets are emerging for specific applications.
For example, hypoxia-activated chk1 inhibitors were recently developed as proof-of-principle molecules for targeting the hypoxic compartment of tumours, where chk1 is an important component of the DNA damage response and cell cycle progression. ${ }^{261}$ From these studies, it is clear that the emerging application of microenvironmental-targeted agents in combination therapies can improve patient outcomes, and as newer generation inhibitors are developed, we are likely to see a wider application of these agents entering the clinic.

\section{CONCLUSIONS}

Given the lagging improvements in therapy, there is a dire need to find new biomarkers and targets to move pancreatic cancer towards personalised medicine approaches (figure 2). To guide clinical success, emerging combinations would benefit from a preclinical platform of evidence in at least one in vivo model, as well as optimisation of solubility for reduced toxicity and, importantly, identification of at least one suitable biomarker for patient stratification at the level of clinical trials (figure 2). The emerging efficacy of PI3K pathway inhibitors for PDAC and the

\section{Box 2 What may improve clinical trials?}

- Patient subtyping from tumour biopsies by genomic and/or mass spectrometry approaches.

- Biomarker identification prior to progression to phase II/ III studies to ensure appropriate patient stratification for maximal benefit (circulating cell-free DNA/genomic approaches/lHC).

- Incorporation of non-invasive imaging for hypoxic tumour burden, such as electron paramagnetic resonance imaging, MRI or positron emission tomography with ${ }^{18} \mathrm{~F}$-fluorodeoxyglucose.

- Testing of promising lead compounds against stratified patient-derived xenograft/Avatar cohorts prior to phase I clinical trials.

- Development of new prodrugs to use in combination therapies with reduced off-target effects.

- Raising the bar when defining preclinical 'success'. 
convergence of several aberrantly expressed signalling cascades highlights a clear progression towards their application for this disease. For example, patients with aberrant DNA damage repair pathways have responded well to PI3K pathway inhibition as part of combination therapies, and trials are already underway in PDAC. Furthermore, given the complex dimerisation of the ErbB family of RTKs and the association of Ephrin receptors with more aggressive PDAC subtypes, RTKs may provide biomarkers for patients that would respond efficaciously to PI3K pathway inhibition. Moving forward, one of the key goals of the ICGC2 is to link bioinformatics approaches, such as molecular subtyping of patients, to clinical data, and we expect this to drive an increase in biomarker-driven clinical trials (proposed in box 2). This is a necessary step to decrease the attrition of lead compounds in the pharmaceutical industry and to ensure that next-generation inhibitors progress to patients that are appropriately subtyped for maximum benefit.

Acknowledgements The authors would like to thank Dr Marina Pajic, Dr David R Croucher and Kendelle J Murphy for critical reading of the manuscript.

Contributors JRWC and PT developed the main concept of the manuscript. All authors wrote the manuscript. JPM and PT wrote grant applications that funded the work.

Funding This work was supported by an Nation Health and Medical Research (NHMRC) project grant, an NHMRC fellowship, an Nation Breast Cancer Foundation (NBCF) grant, an Australian Research Council (ARC) Future fellowship, a Len Ainsworth Pancreatic Cancer Fellowship, Cancer Council NSW grant, a Tour de Cure grant and Cancer Research UK (CRUK) core funding (A17196 and A21139). This project was made possible by an Avner Pancreatic Cancer Foundation Grant.

Competing interests None declared.

Patient consent Not required.

Provenance and peer review Commissioned; externally peer reviewed.

Open access This is an open access article distributed in accordance with the Creative Commons Attribution 4.0 Unported (CC BY 4.0) license, which permits others to copy, redistribute, remix, transform and build upon this work for any purpose, provided the original work is properly cited, a link to the licence is given, and indication of whether changes were made. See: https://creativecommons.org/ licenses/by/4.0/.

\section{REFERENCES}

1 Raimondi S, Maisonneuve P, Lowenfels AB. Epidemiology of pancreatic cancer: an overview. Nat Rev Gastroenterol Hepatol 2009;6:699-708.

2 Rahib L, Smith BD, Aizenberg R, et al. Projecting cancer incidence and deaths to 2030: the unexpected burden of thyroid, liver, and pancreas cancers in the United States. Cancer Res 2014;74:2913-21.

3 Siegel RL, Miller KD, Jemal A. Cancer statistics. CA: a cancer journal for clinicians, 2018;68:7-30.

4 Greenlee RT, Murray T, Bolden S, et al. Cancer statistics. CA: A Cancer Journal for Clinicians;2000:50:7-33.

5 Burris HA, Moore MJ, Andersen J, et al. Improvements in survival and clinical benefit with gemcitabine as first-line therapy for patients with advanced pancreas cancer: a randomized trial. J Clin Oncol 1997;15:2403-13.

6 Winter JM, Brennan MF, Tang LH, et al. Survival after resection of pancreatic adenocarcinoma: results from a single institution over three decades. Ann Surg Oncol 2012:19:169-75.

7 Neoptolemos JP, Stocken DD, Friess H, et al. A randomized trial of chemoradiotherapy and chemotherapy after resection of pancreatic cancer. N Eng/ I Med Overseas Ed 2004;350:1200-10

8 Oettle H, Neuhaus P, Hochhaus A, et al. Adjuvant chemotherapy with gemcitabine and long-term outcomes among patients with resected pancreatic cancer: the CONKO-001 randomized trial. JAMA 2013:310:1473-81.

9 Chang DK, Johns AL, Merrett ND, et al. Margin clearance and outcome in resected pancreatic cancer. J Clin Oncol 2009;27:2855-62.

10 Donahue TR, Reber HA. Surgical management of pancreatic cancerpancreaticoduodenectomy. Semin Oncol 2015;42:98-109.

11 Parikh PY, Lillemoe KD. Surgical management of pancreatic cancer-distal pancreatectomy. Semin Oncol 2015;42:110-22.

12 Ahn DH, Krishna K, Blazer M, et al. A modified regimen of biweekly gemcitabine and nab-paclitaxel in patients with metastatic pancreatic cancer is both tolerable and effective: a retrospective analysis. Ther Adv Med Oncol 2017;9:75-82.

13 Hidalgo M. Pancreatic cancer. N Engl J Med Overseas Ed 2010;362:1605-17.
14 Von Hoff DD, Ervin T, Arena FP, et al. Increased survival in pancreatic cancer with nab-paclitaxel plus gemcitabine. N Eng/ J Med 2013:369:1691-703.

15 Garrido-Laguna I, Hidalgo M. Pancreatic cancer: from state-of-the-art treatments to promising novel therapies. Nat Rev Clin Oncol 2015:12:319-34.

16 Conroy T, Desseigne F, Ychou M, et al. FOLFIRINOX versus gemcitabine for metastatic pancreatic cancer. N Engl J Med Overseas Ed 2011;364:1817-25.

17 Hruban RH, Goggins M, Parsons J, et al. Progression model for pancreatic cancer. Clin Cancer Res 2000:6:2969-72.

18 Bardeesy N, DePinho RA. Pancreatic cancer biology and genetics. Nat Rev Cancer 2002;2:897-909.

19 Klein WM, Hruban RH, Klein-Szanto AJ, et al. Direct correlation between proliferative activity and dysplasia in pancreatic intraepithelial neoplasia (PanIN): additional evidence for a recently proposed model of progression. Mod Pathol 2002:15:441-7.

20 Makohon-Moore A, lacobuzio-Donahue CA. Pancreatic cancer biology and genetics from an evolutionary perspective. Nat Rev Cancer 2016;16:553-65.

21 Hruban RH, Maitra A, Goggins M. Update on pancreatic intraepithelial neoplasia. Int $J$ Clin Exp Pathol 2008:1:306-16.

22 Basturk $\mathrm{O}$, Hong SM, Wood LD, et al. A revised classification system and recommendations from the baltimore consensus meeting for neoplastic precursor lesions in the pancreas. Am J Surg Pathol 2015;39:1730-41.

23 Pinho AV, Rooman I, Reichert M, et al. Adult pancreatic acinar cells dedifferentiate to an embryonic progenitor phenotype with concomitant activation of a senescence programme that is present in chronic pancreatitis. Gut 2011;60:958-66.

24 Jensen JN, Cameron E, Garay MVR, et al. Recapitulation of elements of embryonic development in adult mouse pancreatic regeneration. Gastroenterology 2005:128:728-41.

25 Shi C, Hong SM, Lim P, et al. KRAS2 mutations in human pancreatic acinar-ductal metaplastic lesions are limited to those with PanIN: implications for the human pancreatic cancer cell of origin. Mol Cancer Res 2009;7:230-6.

26 Kanda M, Matthaei $\mathrm{H}, \mathrm{Wu}$ J, et al. Presence of somatic mutations in most early-stage pancreatic intraepithelial neoplasia. Gastroenterology 2012;142:730-3.

27 Notta F, Chan-Seng-Yue M, Lemire M, et al. A renewed model of pancreatic cancer evolution based on genomic rearrangement patterns. Nature 2016;538:378-82.

28 Schönhuber N, Seidler B, Schuck K, et al. A next-generation dual-recombinase system for time- and host-specific targeting of pancreatic cancer. Nat Med 2014;20:1340-7

29 Maitra A, Fukushima N, Takaori K, et al. Precursors to invasive pancreatic cancer. Adv Anat Pathol 2005;12:81-91.

30 Castellano-Megías VM, Andrés Cl, López-Alonso G, et al. Pathological features and diagnosis of intraductal papillary mucinous neoplasm of the pancreas. World $J$ Gastrointest Oncol 2014:6:311-24.

31 Matthaei H, Schulick RD, Hruban RH, et al. Cystic precursors to invasive pancreatic cancer. Nat Rev Gastroenterol Hepatol 2011;8:141-50.

32 Biankin AV, Kench JG, Biankin SA, et al. Pancreatic intraepithelial neoplasia in association with intraductal papillary mucinous neoplasms of the pancreas: implications for disease progression and recurrence. Am I Surg Pathol 2004;28:1184-92.

33 Tanaka M, Chari S, Adsay V, et al. International consensus quidelines for management of intraductal papillary mucinous neoplasms and mucinous cystic neoplasms of the pancreas. Pancreatology 2006;6:17-32.

34 Haugk B. Pancreatic intraepithelial neoplasia-can we detect early pancreatic cancer? Histopathology 2010;57:503-14.

35 Yonezawa S, Higashi M, Yamada N, et al. Significance of mucin expression in pancreatobiliary neoplasms.J Hepatobiliary Pancreat Sci 2010;17:108-24.

36 van Heek NT, Meeker AK, Kern SE, et al. Telomere shortening is nearly universal in pancreatic intraepithelial neoplasia. Am J Pathol 2002;161:1541-7.

37 Moskaluk CA, Hruban RH, Kern SE. p16 and K-ras gene mutations in the intraductal precursors of human pancreatic adenocarcinoma. Cancer Res 1997;57:2140-3.

38 Biankin AV, Waddell N, Kassahn KS, et al. Pancreatic cancer genomes reveal aberrations in axon guidance pathway genes. Nature 2012;491:399-405

39 Heinmöller E, Dietmaier W, Zirngibl H, et al. Molecular analysis of microdissected tumors and preneoplastic intraductal lesions in pancreatic carcinoma. Am J Pathol 2000;157:83-92

40 Collisson EA, Sadanandam A, Olson P, et al. Subtypes of pancreatic ductal adenocarcinoma and their differing responses to therapy. Nat Med 2011;17:500-3.

41 Moffitt RA, Marayati R, Flate EL, et al. Virtual microdissection identifies distinct tumor- and stroma-specific subtypes of pancreatic ductal adenocarcinoma. Nat Genet 2015;47:1168-78

42 Bailey $\mathrm{P}$, Chang DK, Nones K, et al. Genomic analyses identify molecular subtypes of pancreatic cancer. Nature 2016:531:47-52.

43 Humphrey ES, Su SP, Nagrial AM, et al. Resolution of novel pancreatic ductal adenocarcinoma subtypes by global phosphotyrosine profiling. Mol Cell Proteomics 2016;15:2671-85

44 Jones S, Zhang X, Parsons DW, et al. Core signaling pathways in human pancreatic cancers revealed by global genomic analyses. Science 2008;321:1801-6.

45 Erkan M, Michalski CW, Rieder S, et al. The activated stroma index is a novel and independent prognostic marker in pancreatic ductal adenocarcinoma. Clin Gastroenterol Hepatol 2008;6:1155-61. 
46 Daemen A, Peterson D, Sahu N, et al. Metabolite profiling stratifies pancreatic ducta adenocarcinomas into subtypes with distinct sensitivities to metabolic inhibitors. Proc Natl Acad Sci U S A 2015;112:E4410-E4417.

47 Vennin C, Murphy KJ, Morton JP, et al. Reshaping the Tumor Stroma for Treatment of Pancreatic Cancer. Gastroenterology 2018;154:820-38.

48 lacobuzio-Donahue CA, Maitra A, Olsen M, et al. Exploration of global gene expression patterns in pancreatic adenocarcinoma using cDNA microarrays. Am J Pathol 2003; 162:1151-62.

49 Nicolle R, Blum Y, Marisa L, et al. Pancreatic adenocarcinoma therapeutic targets revealed by tumor-stroma cross-talk analyses in patient-derived xenografts. Cell Rep 2017:21:2458-70.

50 Waddell N, Pajic M, Patch AM, et al. Whole genomes redefine the mutational landscape of pancreatic cancer. Nature 2015:518:495-501.

51 Yoshihara K, Shahmoradgoli M, Martínez E, et al. Inferring tumour purity and stromal and immune cell admixture from expression data. Nat Commun 2013:4:2612.

52 Conway JR, Carragher NO, Timpson P. Developments in preclinical cancer imaging: innovating the discovery of therapeutics. Nat Rev Cancer 2014;14:314-28.

53 Biankin AV, Piantadosi S, Hollingsworth SJ. Patient-centric trials for therapeutic development in precision oncology. Nature 2015:526:361-70.

54 Crane $\mathrm{CH}$, lacobuzio-Donahue CA. Keys to personalized care in pancreatic oncology. J Clin Oncol 2012;30:4049-950.

55 Le Tourneau C, Delord JP, Gonçalves A, et al. Molecularly targeted therapy based on tumour molecular profiling versus conventional therapy for advanced cancer (SHIVA): a multicentre, open-label, proof-of-concept, randomised, controlled phase 2 trial. Lancet Oncol 2015;16:1324-34.

56 Chantrill LA, Nagrial AM, Watson C, et al. Precision medicine for advanced pancreas cancer: The individualized Molecular Pancreatic Cancer Therapy (IMPaCT) Trial. Clin Cancer Res 2015:21:2029-37.

57 Janku F, Yap TA, Meric-Bernstam F. Targeting the PI3K pathway in cancer: are we making headway? Nat Rev Clin Oncol 2018;15:273-91.

58 Liu P, Cheng H, Roberts TM, et al. Targeting the phosphoinositide 3-kinase pathway in cancer. Nat Rev Drug Discov 2009;8:627-44.

59 Hollander MC, Blumenthal GM, Dennis PA. PTEN loss in the continuum of common cancers, rare syndromes and mouse models. Nat Rev Cancer 2011;11:289-301.

60 Dancey J. mTOR signaling and drug development in cancer. Nat Rev Clin Oncol 2010;7:209-19.

61 Manning BD, Cantley LC. AKT/PKB signaling: navigating downstream. Cell 2007; 129:1261-74.

62 Duluc C, Moatassim-Billah S, Chalabi-Dchar M, et al. Pharmacological targeting of the protein synthesis mTOR/4E-BP1 pathway in cancer-associated fibroblasts abrogates pancreatic tumour chemoresistance. EMBO Mol Med 2015;7:735-53.

63 Graupera M, Guillermet-Guibert J, Foukas LC, et al. Angiogenesis selectively requires the p110alpha isoform of PI3K to control endothelial cell migration. Nature 2008;453:662-6.

64 Kaneda MM, Cappello P, Nguyen AV, et al. Macrophage PI3K $\gamma$ Drives Pancreatic Ductal Adenocarcinoma Progression. Cancer Discov 2016;6:870-85.

65 Chi H. Regulation and function of mTOR signalling in T cell fate decisions. Nat Rev Immunol 2012;12:325-38

66 Ruggeri BA, Huang L, Wood M, et al. Amplification and overexpression of the AKT2 oncogene in a subset of human pancreatic ductal adenocarcinomas. Mol Carcinog 1998;21:81-6

67 Cheng JQ, Ruggeri B, Klein WM, et al. Amplification of AKT2 in human pancreatic cells and inhibition of AKT2 expression and tumorigenicity by antisense RNA. Proc Natl Acad Sci U SA 1996:93:3636-41.

68 Schlieman MG, Fahy BN, Ramsamooj R, et al. Incidence, mechanism and prognostic value of activated AKT in pancreas cancer. Br J Cancer 2003;89:2110-5.

69 Janku F, Hong DS, Fu S, et al. Assessing PIK3CA and PTEN in early-phase trials with $\mathrm{PI3K} / \mathrm{AKT} / \mathrm{mTOR}$ inhibitors. Cell Rep 2014;6:377-87.

70 Witkiewicz AK, McMillan EA, Balaji U, et al. Whole-exome sequencing of pancreatic cancer defines genetic diversity and therapeutic targets. Nat Commun 2015;6:6744.

71 Ying $H$, Elpek KG, Vinjamoori $A$, et al. PTEN is a major tumor suppressor in pancreatic ductal adenocarcinoma and regulates an NF- $\mathrm{\kappa B}$-cytokine network. Cancer Discov 2011:1:158-69.

72 Foo WC, Rashid A, Wang H, et al. Loss of phosphatase and tensin homolog expression is associated with recurrence and poor prognosis in patients with pancreatic ductal adenocarcinoma. Hum Pathol 2013:44:1024-30.

73 Kennedy AL, Morton JP, Manoharan I, et al. Activation of the PIK3CA/AKT pathway suppresses senescence induced by an activated RAS oncogene to promote tumorigenesis. Mol Cell 2011;42:36-49.

74 Eser S, Reiff N, Messer M, et al. Selective requirement of PI3K/PDK1 signaling for Kras oncogene-driven pancreatic cell plasticity and cancer. Cancer Cell 2013:23:406-20.

75 Wu CY, Carpenter ES, Takeuchi KK, et al. PI3K regulation of RAC1 is required for KRAS-induced pancreatic tumorigenesis in mice. Gastroenterology 2014:147:1405-16.

76 Baer R, Cintas C, Dufresne M, et al. Pancreatic cell plasticity and cancer initiation induced by oncogenic Kras is completely dependent on wild-type PI 3-kinase p110 $\alpha$. Genes Dev 2014;28:2621-35.
77 Kodahl AR, Ehmsen S, Pallisgaard N, et al. Correlation between circulating cell-free PIK3CA tumor DNA levels and treatment response in patients with PIK3CA-mutated metastatic breast cancer. Mol Oncol 2018;12:925-35.

78 Payne SN, Maher ME, Tran NH, et al. PIK3CA mutations can initiate pancreatic tumorigenesis and are targetable with PI3K inhibitors. Oncogenesis 2015;4:e169.

79 Frenel JS, Carreira S, Goodall J, et al. Serial next-generation sequencing of circulating cell-free dna evaluating tumor clone response to molecularly targeted drug administration. Clin Cancer Res 2015:21:4586-96.

80 Thorpe LM, Yuzugullu H, Zhao JJ. PI3K in cancer: divergent roles of isoforms, modes of activation and therapeutic targeting. Nat Rev Cancer 2015;15:7-24.

81 Yap TA, Bjerke L, Clarke PA, et al. Drugging PI3K in cancer: refining targets and therapeutic strategies. Curr Opin Pharmacol 2015;23:98-107.

82 Wong MH, Xue A, Julovi SM, et al. Cotargeting of epidermal growth factor receptor and PI3K overcomes PI3K-Akt oncogenic dependence in pancreatic ductal adenocarcinoma. Clin Cancer Res 2014;20:4047-58.

83 Gasser JA, Inuzuka H, Lau AW, et al. SGK3 mediates INPP4B-dependent PI3K signaling in breast cancer. Mol Cell 2014:56:595-607.

84 Driscoll DR, Karim SA, Sano M, et al. mTORC2 Signaling drives the development and progression of pancreatic cancer. Cancer Res 2016;76:6911-23.

85 Khalil BD, Hsueh C, Cao Y, et al. GPCR Signaling Mediates Tumor Metastasis via PI3Kß. Cancer Res 2016;76:2944-53.

86 Zhang Z, Liu J, Wang Y, et al. Phosphatidylinositol 3-kinase $\beta$ and $\delta$ isoforms play key roles in metastasis of prostate cancer DU145 cells. The FASEB Journal 2018:fj.201800183R.

87 Ali K, Soond DR, Pineiro R, et al. Inactivation of PI(3)K p110 1 breaks regulatory T-cell-mediated immune tolerance to cancer. Nature 2014;510:407-11.

88 Mann KM, Ward JM, Yew CC, et al. Sleeping Beauty mutagenesis reveals cooperating mutations and pathways in pancreatic adenocarcinoma. Proc Natl Acad Sci U S A 2012;109:5934-41.

89 Pérez-Mancera PA, Rust AG, van der Weyden L, et al. The deubiquitinase USP9X suppresses pancreatic ductal adenocarcinoma. Nature 2012;486:266-70.

90 Kothari V, Wei I, Shankar S, et al. Outlier kinase expression by RNA sequencing as targets for precision therapy. Cancer Discov 2013;3:280-93.

91 Seto B. Rapamycin and mTOR: a serendipitous discovery and implications for breast cancer. Clin Trans/ Med 2012:1:29.

92 Morran DC, Wu J, Jamieson NB, et al. Targeting mTOR dependency in pancreatic cancer. Gut 2014:63:1481-9.

93 Yao JC, Shah MH, Ito T, et al. Everolimus for advanced pancreatic neuroendocrine tumors. N Engl J Med Overseas Ed 2011:364:514-23.

94 Wolpin BM, Hezel AF, Abrams T, et al. Oral mTOR inhibitor everolimus in patients with gemcitabine-refractory metastatic pancreatic cancer. J Clin Oncol 2009;27:193-8

95 Javle MM, Shroff RT, Xiong $H$, et al. Inhibition of the mammalian target of rapamycin (mTOR) in advanced pancreatic cancer: results of two phase II studies. BMC Cancer 2010;10:368.

96 Sun SY, Rosenberg LM, Wang X, et al. Activation of Akt and elF4E survival pathways by rapamycin-mediated mammalian target of rapamycin inhibition. Cancer Res 2005;65:7052-8.

97 O'Reilly KE, Rojo F, She QB, et al. mTOR inhibition induces upstream receptor tyrosine kinase signaling and activates Akt. Cancer Res 2006:66:1500-8.

98 Basu B, Dean E, Puglisi M, et al. First-in-human pharmacokinetic and pharmacodynamic study of the dual m-TORC 1/2 inhibitor AZD2014. Clin Cancer Res 2015:21:3412-9.

99 Kordes S, Richel DJ, Klümpen HJ, et al. A phase I/II, non-randomized, feasibility/safety and efficacy study of the combination of everolimus, cetuximab and capecitabine in patients with advanced pancreatic cancer. Invest New Drugs 2013;31:85-91.

100 Cartwright TH, Cohn A, Varkey JA, et al. Phase II study of oral capecitabine in patients with advanced or metastatic pancreatic cancer. J Clin Oncol 2002:20:160-4

101 Andrs M, Korabecny J, Jun D, et al. Phosphatidylinositol 3-Kinase (PI3K) and Phosphatidylinositol 3-Kinase-related Kinase (PIKK) inhibitors: importance of the morpholine ring. J Med Chem 2015;58:41-71.

102 Liu Y, Wan WZ, Li Y, et al. Recent development of ATP-competitive small molecule phosphatidylinostitol-3-kinase inhibitors as anticancer agents. Oncotarget 2017:8:7181-200

103 Kawada H, Ebiike $\mathrm{H}$, Tsukazaki M, et al. Optimization of the phenylurea moiety in a phosphoinositide 3-kinase (PI3K) inhibitor to improve water solubility and the PK profile by introducing a solubilizing group and ortho substituents. Bioorg Med Chem 2016;24:2897-906.

104 Pike KG, Malagu K, Hummersone MG, et al. Optimization of potent and selective dual mTORC1 and mTORC2 inhibitors: the discovery of AZD8055 and AZD2014. Bioorg Med Chem Lett 2013;23:1212-6.

105 Conway JRW, Warren SC, Herrmann D, et al. Intravital Imaging to Monitor Therapeutic Response in Moving Hypoxic Regions Resistant to PI3K Pathway Targeting in Pancreatic Cancer. Cell Rep 2018;23:3312-26.

106 Yoshikawa Y, Takano O, Kato I, et al. Ras inhibitors display an anti-metastatic effect by downregulation of lysyl oxidase through inhibition of the Ras-PI3K-Akt-HIF- $1 \alpha$ pathway. Cancer Lett 2017;410:82-91. 
107 Zhao L, Li C, Liu F, et al. A blockade of PD-L1 produced antitumor and antimetastatic effects in an orthotopic mouse pancreatic cancer model via the PI3K/Akt/mTOR signaling pathway. Onco Targets Ther 2017;10:2115-26.

108 Ooms LM, Binge LC, Davies EM, et al. The Inositol Polyphosphate 5-Phosphatase PIPP Regulates AKT1-Dependent Breast Cancer Growth and Metastasis. Cancer Cell 2015;28:155-69.

109 Rumman M, Jung KH, Fang Z, et al. HS-173, a novel PI3K inhibitor suppresses EMT and metastasis in pancreatic cancer. Oncotarget 2016:7:78029-47.

110 Arboleda MJ, Lyons JF, Kabbinavar FF, et al. Overexpression of AKT2/protein kinase Bbeta leads to up-regulation of beta1 integrins, increased invasion, and metastasis of human breast and ovarian cancer cells. Cancer Res 2003:63:196-206.

111 Yoeli-Lerner M, Yiu GK, Rabinovitz I, et al. Akt blocks breast cancer cell motility and invasion through the transcription factor NFAT. Mol Cell 2005;20:539-50.

112 Zhou GL, Tucker DF, Bae SS, et al. Opposing roles for Akt1 and Akt2 in Rac/Pak signaling and cell migration. J Biol Chem 2006;281:36443-53.

113 Irie HY, Pearline RV, Grueneberg D, et al. Distinct roles of Akt1 and Akt2 in regulating cell migration and epithelial-mesenchymal transition. J Cell Biol 2005;171:1023-34.

114 Hutchinson JN, Jin J, Cardiff RD, et al. Activation of Akt-1 (PKB-alpha) can accelerate ErbB-2-mediated mammary tumorigenesis but suppresses tumor invasion. Cancer Res 2004:64:3171-8.

115 Gulhati P, Bowen KA, Liu J, et al. mTORC1 and mTORC2 regulate EMT, motility, and metastasis of colorectal cancer via RhoA and Rac1 signaling pathways. Cancer Res 2011:71:3246-56.

116 Hsieh AC, Liu Y, Edlind MP, et al. The translational landscape of mTOR signalling steers cancer initiation and metastasis. Nature 2012:485:55-

117 Klümpen HJ, Queiroz KC, Spek CA, et al. mTOR inhibitor treatment of pancreatic cancer in a patient With Peutz-Jeghers syndrome. J Clin Oncol 2011;29:e150-e153.

118 Yamanaka Y, Friess H, Kobrin MS, et al. Coexpression of epidermal growth factor receptor and ligands in human pancreatic cancer is associated with enhanced tumor aggressiveness. Anticancer Res 1993;13:565-9.

119 Korc M, Chandrasekar B, Yamanaka Y, et al. Overexpression of the epidermal growth factor receptor in human pancreatic cancer is associated with concomitant increases in the levels of epidermal growth factor and transforming growth factor alpha. J Clin Invest 1992:90:1352-60.

120 Ueda S, Ogata S, Tsuda H, et al. The correlation between cytoplasmic overexpression of epidermal growth factor receptor and tumor aggressiveness: poor prognosis in patients with pancreatic ductal adenocarcinoma. Pancreas 2004;29:e1-8.

121 Moore MJ, Goldstein D, Hamm J, et al. Erlotinib plus gemcitabine compared with gemcitabine alone in patients with advanced pancreatic cancer: a phase III trial of the National Cancer Institute of Canada Clinical Trials Group. J Clin Oncol 2007;25:1960-6.

122 Sinn M, Bahra M, Liersch T, et al. Conko-005: Adjuvant chemotherapy with gemcitabine plus erlotinib versus gemcitabine alone in patients after RO resection of pancreatic cancer: A multicenter randomized phase III trial. J Clin Oncol 2017:35:3330-7.

123 Boeck S, Jung A, Laubender RP, et al. KRAS mutation status is not predictive for objective response to anti-EGFR treatment with erlotinib in patients with advanced pancreatic cancer. J Gastroenterol 2013;48:544-8.

124 Boeck S, Jung A, Laubender RP, et al. EGFR pathway biomarkers in erlotinib-treated patients with advanced pancreatic cancer: translational results from the randomised crossover phase 3 trial AIO-PK0104. Br J Cancer 2013;108:469-76.

125 da Cunha Santos G, Dhani N, Tu D, et al. Molecular predictors of outcome in a phase 3 study of gemcitabine and erlotinib therapy in patients with advanced pancreatic cancer: National Cancer Institute of Canada Clinical Trials Group Study PA.3. Cancer 2010;116:5599-607.

126 Wang JP, Wu CY, Yeh YC, et al. Erlotinib is effective in pancreatic cancer with epidermal growth factor receptor mutations: a randomized, open-label, prospective trial. Oncotarget 2015:6:18162-73.

127 Frolov A, Schuller K, Tzeng CW, et al. ErbB3 expression and dimerization with EGFR influence pancreatic cancer cell sensitivity to erlotinib. Cancer Biol Ther 2007;6:548-54.

128 Buck E, Eyzaguirre A, Haley JD, et al. Inactivation of Akt by the epidermal growth factor receptor inhibitor erlotinib is mediated by HER-3 in pancreatic and colorectal tumor cell lines and contributes to erlotinib sensitivity. Mol Cancer Ther 2006;5:2051-9.

129 Friess $H$, Yamanaka Y, Kobrin MS, et al. Enhanced erbB-3 expression in human pancreatic cancer correlates with tumor progression. Clin Cancer Res 1995; 1:1413-20

130 Gingras I, Gebhart G, de Azambuja E, et al. HER2-positive breast cancer is lost in translation: time for patient-centered research. Nat Rev Clin Oncol 2017;14:669-81.

131 Chou A, Waddell N, Cowley MJ, et al. Clinical and molecular characterization of HER2 amplified-pancreatic cancer. Genome Med 2013;5:78.

132 Safran H, Steinhoff M, Mangray S, et al. Overexpression of the HER-2/neu oncogene in pancreatic adenocarcinoma. Am J Clin Oncol 2001;24:496-9.

133 Harder J, Ihorst G, Heinemann V, et al. Multicentre phase II trial of trastuzumab and capecitabine in patients with HER2 overexpressing metastatic pancreatic cancer. $\mathrm{Br}$ J Cancer 2012;106:1033-8.
134 Safran $H$, lannitti D, Ramanathan $R$, et al. Herceptin and gemcitabine for metastatic pancreatic cancers that overexpress HER-2/neu. Cancer Invest 2004:22:706-12.

135 Mill CP, Gettinger KL, Riese II DJ. Ligand stimulation of ErbB4 and a constitutivelyactive ErbB4 mutant result in different biological responses in human pancreatic tumor cell lines. Exp Cell Res 2011;317:392-404.

136 Normanno N, De Luca A, Bianco C, et al. Epidermal growth factor receptor (EGFR) signaling in cancer. Gene 2006;366:2-16.

137 Zhang $\mathrm{H}$, Hylander BL, LeVea C, et al. Enhanced FGFR signalling predisposes pancreatic cancer to the effect of a potent FGFR inhibitor in preclinical models. $\mathrm{Br}$ Cancer 2014:110:320-9.

138 Muzumdar MD, Chen PY, Dorans KJ, et al. Survival of pancreatic cancer cells lacking KRAS function. Nat Commun 2017:8:1090.

139 Coleman SJ, Chioni AM, Ghallab M, et al. Nuclear translocation of FGFR1 and FGF2 in pancreatic stellate cells facilitates pancreatic cancer cell invasion. EMBO Mol Med 2014:6:467-81.

140 Kleeff J, Fukahi K, Lopez ME, et al. Targeting of suicide gene delivery in pancreatic cancer cells via FGF receptors. Cancer Gene Ther 2002:9:522-32.

141 Jindal V, Arora E, Masab M, et al. Chimeric antigen receptor T cell therapy in pancreatic cancer: from research to practice. Med Oncol 2018;35:84.

142 Kratschmer C, Levy M. Targeted delivery of auristatin-modified toxins to pancreatic cancer using aptamers. Mol Ther Nucleic Acids 2018;10:227-36.

143 Man YKS, Davies JA, Coughlan L, et al. THe novel oncolytic adenoviral mutant Ad5$3 \triangle-A 20 T$ retargeted to $\alpha v \beta 6$ integrins efficiently eliminates pancreatic cancer cells. Mol Cancer Ther 2018;17:575-87.

144 Qian C, Wang Y, Chen Y, et al. Suppression of pancreatic tumor growth by targeted arsenic delivery with anti-CD44v6 single chain antibody conjugated nanoparticles. Biomaterials 2013;34:6175-84.

145 Weissmueller $S$, Manchado E, Saborowski M, et al. Mutant p53 drives pancreatic cancer metastasis through cell-autonomous PDGF receptor $\beta$ signaling. Cell 2014;157:382-94.

146 Kurahara H, Maemura K, Mataki Y, et al. Impact of p53 and PDGFR- $\beta$ Expression on Metastasis and Prognosis of Patients with Pancreatic Cancer. World I Surg 2016:40:1977-84

147 Pàez-Ribes M, Allen E, Hudock J, et al. Antiangiogenic therapy elicits malignant progression of tumors to increased local invasion and distant metastasis. Cancer Cell 2009;15:220-31.

148 Raymond E, Dahan L, Raoul J-L, et al. Sunitinib malate for the treatment of pancreatic neuroendocrine tumors. N Eng/ J Med Overseas Ed 2011;364:501-13.

149 Nemunaitis J, Hochster HS, Lustgarten S, et al. A phase I trial of oral ridaforolimus (AP23573; MK-8669) in combination with bevacizumab for patients with advanced cancers. Clin Oncol 2013;25:336-42.

150 Gangadhar TC, Cohen EE, Wu K, et al. Two drug interaction studies of sirolimus in combination with sorafenib or sunitinib in patients with advanced malignancies. Clin Cancer Res 2011:17:1956-63.

151 Martínez-Bosch N, Guerrero PE, Moreno M, et al. The pancreatic niche inhibits the effectiveness of sunitinib treatment of pancreatic cancer. Oncotarget 2016;7:48265-79

152 O'Reilly EM, Niedzwiecki D, Hall M, et al. A Cancer and Leukemia Group B phase II study of sunitinib malate in patients with previously treated metastatic pancreatic adenocarcinoma (CALGB 80603). Oncologist 2010;15:1310-9.

153 Fischer $C$, Jonckx B, Mazzone M, et al. Anti-PIGF inhibits growth of VEGF(R)inhibitor-resistant tumors without affecting healthy vessels. Cell 2007:131:463-75.

154 Hedlund EM, Yang X, Zhang Y, et al. Tumor cell-derived placental growth factor sensitizes antiangiogenic and antitumor effects of anti-VEGF drugs. Proc Nat/ Acad Sci U S A 2013:110:654-9.

155 Lu Z, Zhang Y, Li Z, et al. Overexpression of the B-type Eph and ephrin genes correlates with progression and pain in human pancreatic cancer. Oncol Lett 2012;3:1207-12.

156 Giaginis C, Tsourouflis G, Zizi-Serbetzoglou A, et al. Clinical significance of ephrin (eph)-A1, -A2, -a4, -a5 and -a7 receptors in pancreatic ductal adenocarcinoma. Pathol Oncol Res 2010;16:267-76.

157 Gundry C, Marco S, Rainero E, et al. Phosphorylation of Rab-coupling protein by LMTK3 controls Rab14-dependent EphA2 trafficking to promote cell:cell repulsion. Nat Commun 2017:8:14646.

158 Boyd AW, Bartlett PF, Lackmann M. Therapeutic targeting of EPH receptors and their ligands. Nat Rev Drug Discov 2014;13:39-62.

159 Annunziata CM, Kohn EC, LoRusso P, et al. Phase 1, open-label study of MEDI-547 in patients with relapsed or refractory solid tumors. Invest New Drugs 2013:31:77-84.

160 Chang Q, Jorgensen C, Pawson T, et al. Effects of dasatinib on EphA2 receptor tyrosine kinase activity and downstream signalling in pancreatic cancer. Br J Cancer 2008:99:1074-82.

161 Li J, Rix U, Fang B, et al. A chemical and phosphoproteomic characterization of dasatinib action in lung cancer. Nat Chem Biol 2010;6:291-9.

162 Shi H, Zhang CJ, Chen GY, et al. Cell-based proteome profiling of potential dasatinib targets by use of affinity-based probes. J Am Chem Soc 2012;134:3001-14.

163 Morton JP, Karim SA, Graham K, et al. Dasatinib inhibits the development of metastases in a mouse model of pancreatic ductal adenocarcinoma. Gastroenterology 2010;139:292-303. 
164 Evans TRJ, Van Cutsem E, Moore MJ, et al. Phase 2 placebo-controlled, double-blind trial of dasatinib added to gemcitabine for patients with locally-advanced pancreatic cancer. Ann Oncol 2017;28:354-61.

165 Neuzillet $C$, de Gramont A, Tijeras-Raballand A, et al. Perspectives of TGF- $\beta$ inhibition in pancreatic and hepatocellular carcinomas. Oncotarget 2014;5:78-94.

166 Blackford A, Serrano OK, Wolfgang CL, et al. SMAD4 gene mutations are associated with poor prognosis in pancreatic cancer. Clin Cancer Res 2009;15:4674-9.

167 lacobuzio-Donahue CA, Fu B, Yachida S, et al. DPC4 gene status of the primary carcinoma correlates with patterns of failure in patients with pancreatic cancer. $J$ Clin Oncol 2009;27:1806-13.

168 Herman JM, Fan KY, Wild AT, et al. Correlation of Smad4 status with outcomes in patients receiving erlotinib combined with adjuvant chemoradiation and chemotherapy after resection for pancreatic adenocarcinoma. Int J Radiat Oncol Biol Phys 2013;87:458-9.

169 Subramanian G, Schwarz RE, Higgins L, et al. Targeting endogenous transforming growth factor beta receptor signaling in SMAD4-deficient human pancreatic carcinoma cells inhibits their invasive phenotype1. Cancer Res 2004;64:5200-11.

170 Serova M, Tijeras-Raballand A, Dos Santos C, et al. Effects of TGF-beta signalling inhibition with galunisertib (LY2157299) in hepatocellular carcinoma models and in ex vivo whole tumor tissue samples from patients. Oncotarget 2015:6:21614-27.

171 Hamidi A, Song J, Thakur N, et al. TGF- $\beta$ promotes PI3K-AKT signaling and prostate cancer cell migration through the TRAF6-mediated ubiquitylation of $p 85 \alpha$. Sci Signal 2017; 10:eaal4186.

172 Roberts NJ, Norris AL, Petersen GM, et al. Whole genome sequencing defines the genetic heterogeneity of familial pancreatic cancer. Cancer Discov 2016;6:166-75.

173 Petersen GM. Familial pancreatic adenocarcinoma. Hematol Oncol Clin North Am 2015;29:641-53.

174 Levy-Lahad E, Friedman E. Cancer risks among BRCA1 and BRCA2 mutation carriers. Br J Cancer 2007;96:11-15.

175 Breast Cancer Linkage Consortium. Cancer risks in BRCA2 mutation carriers. J Natl Cancer Inst 1999;91:1310-6.

176 Goggins M, Hruban RH, Kern SE. BRCA2 is inactivated late in the development of pancreatic intraepithelial neoplasia: evidence and implications. Am J Pathol 2000;156:1767-71.

177 Kaufman B, Shapira-Frommer R, Schmutzler RK, et al. Olaparib monotherapy in patients with advanced cancer and a germline BRCA1/2 mutation. J Clin Oncol 2015:33:244-50.

178 Farmer H, McCabe N, Lord CJ, et al. Targeting the DNA repair defect in BRCA mutant cells as a therapeutic strategy. Nature 2005;434:917-21.

179 Murai J, Huang SY, Das BB, et al. Trapping of PARP1 and PARP2 by clinical PARP inhibitors. Cancer Res 2012;72:5588-99.

180 Bryant HE, Schultz N, Thomas HD, et al. Specific killing of BRCA2-deficient tumours with inhibitors of poly(ADP-ribose) polymerase. Nature 2005;434:913-7.

181 Villarroel MC, Rajeshkumar NV, Garrido-Laguna I, et al. Personalizing cancer treatment in the age of global genomic analyses: PALB2 gene mutations and the response to DNA damaging agents in pancreatic cancer. Mol Cancer Ther 2011;10:3-8.

182 Philip CA, Laskov I, Beauchamp MC, et al. Inhibition of PI3K-AKT-mTOR pathway sensitizes endometrial cancer cell lines to PARP inhibitors. BMC Cancer 2017:17:638.

183 Juvekar A, Burga LN, Hu H, et al. Combining a PI3K inhibitor with a PARP inhibitor provides an effective therapy for BRCA1-related breast cancer. Cancer Discov 2012;2:1048-63.

184 Ibrahim YH, García-García C, Serra V, et al. PI3K inhibition impairs BRCA1/2 expression and sensitizes BRCA-proficient triple-negative breast cancer to PARP inhibition. Cancer Discov 2012;2:1036-47.

185 Chou A, Froio D, Nagrial AM, et al. Tailored first-line and second-line CDK4targeting treatment combinations in mouse models of pancreatic cancer. Gut 2017:gutjnl-2017-315144

186 Cristofanilli M, Turner NC, Bondarenko I, et al. Fulvestrant plus palbociclib versus fulvestrant plus placebo for treatment of hormone-receptor-positive, HER2negative metastatic breast cancer that progressed on previous endocrine therapy (PALOMA-3): final analysis of the multicentre, double-blind, phase 3 randomised controlled trial. Lancet Oncol 2016;17:425-39.

187 Konecny GE, Winterhoff B, Kolarova T, et al. Expression of p16 and retinoblastoma determines response to CDK4/6 inhibition in ovarian cancer. Clin Cancer Res 2011;17:1591-602

188 Sheppard KE, McArthur GA. The cell-cycle regulator CDK4: an emerging therapeutic target in melanoma. Clin Cancer Res 2013;19:5320-8.

189 Hu C, Dadon T, Chenna V, et al. Combined inhibition of cyclin-dependent kinases (Dinaciclib) and AKT (MK-2206) blocks pancreatic tumor growth and metastases in patient-derived xenograft models. Mol Cancer Ther 2015;14:1532-9.

190 Chiron D, Di Liberto M, Martin P, et al. Cell-cycle reprogramming for PI3K inhibition overrides a relapse-specific C481S BTK mutation revealed by longitudinal functional genomics in mantle cell lymphoma. Cancer Discov 2014;4:1022-35.

191 Morton JP, Timpson P, Karim SA, et al. Mutant p53 drives metastasis and overcomes growth arrest/senescence in pancreatic cancer. Proc Natl Acad Sci U S A 2010;107:246-51.
192 Muller PA, Caswell PT, Doyle B, et al. Mutant p53 drives invasion by promoting integrin recycling. Cell 2009;139:1327-41.

193 Abraham AG, O'Neill E. PI3K/Akt-mediated regulation of p53 in cancer. Biochem Soc Trans 2014:42:798-803.

194 Nayak SK, Panesar PS, Kumar H. p53-Induced apoptosis and inhibitors of p53. Curr Med Chem 2009;16:2627-40.

195 Yan W, Liu S, Xu E, et al. Histone deacetylase inhibitors suppress mutant p53 transcription via histone deacetylase 8. Oncogene 2013:32:599-609.

196 Stojanovic N, Hassan Z, Wirth M, et al. HDAC1 and HDAC2 integrate the expression of p53 mutants in pancreatic cancer. Oncogene 2017;36:1804-15.

197 Giaginis C, Damaskos C, Koutsounas I, et al. Histone deacetylase (HDAC)-1, -2, -4 and -6 expression in human pancreatic adenocarcinoma: associations with clinicopathological parameters, tumor proliferative capacity and patients' survival. BMC Gastroenterol 2015;15:148

198 Koutsounas I, Giaginis C, Theocharis S. Histone deacetylase inhibitors and pancreatic cancer: are there any promising clinical trials? World J Gastroenterol 2013;19:1173-81.

199 Chan E, Arlinghaus LR, Cardin DB, et al. Phase I trial of vorinostat added to chemoradiation with capecitabine in pancreatic cancer. Radiother Oncol 2016;119:312-8

200 Zhang G, Park MA, Mitchell C, et al. Vorinostat and sorafenib synergistically kill tumor cells via FLIP suppression and CD95 activation. Clin Cancer Res 2008:14:5385-99.

201 Dasari A, Gore L, Messersmith WA, et al. A phase I study of sorafenib and vorinostat in patients with advanced solid tumors with expanded cohorts in renal cell carcinoma and non-small cell lung cancer. Invest New Drugs 2013:31:115-25.

202 Wade M, Li YC, Wahl GM. MDM2, MDMX and p53 in oncogenesis and cance therapy. Nat Rev Cancer 2013;13:83-96.

203 Sherr CJ. Divorcing ARF and p53: an unsettled case. Nat Rev Cancer 2006;6:663-73.

204 Mayo LD, Dixon JE, Durden DL, et al. PTEN protects p53 from Mdm2 and sensitizes cancer cells to chemotherapy. J Biol Chem 2002;277:5484-9.

205 Freeman DJ, Li AG, Wei G, et al. PTEN tumor suppressor regulates p53 protein levels and activity through phosphatase-dependent and -independent mechanisms. Cancer Cell 2003;3:117-30

206 Suh YA, Post SM, Elizondo-Fraire AC, et al. Multiple stress signals activate mutant p53 in vivo. Cancer Res 2011;71:7168-75.

207 Azmi AS, Philip PA, Aboukameel A, et al. Reactivation of p53 by novel MDM2 inhibitors: implications for pancreatic cancer therapy. Curr Cancer Drug Targets 2010;10:319-31.

208 Gottlieb TM, Leal JF, Seger R, et al. Cross-talk between Akt, p53 and Mdm2: possible implications for the regulation of apoptosis. Oncogene 2002;21:1299-303.

209 Zhou BP, Liao Y, Xia W, et al. HER-2/neu induces p53 ubiquitination via Akt-mediated MDM2 phosphorylation. Nat Cell Biol 2001;3:973-82.

210 Muller PA, Vousden KH. Mutant p53 in cancer: new functions and therapeutic opportunities. Cancer Cell 2014;25:304-17.

211 Kulikov R, Boehme KA, Blattner C. Glycogen synthase kinase 3-dependent phosphorylation of Mdm2 regulates p53 abundance. $\mathrm{Mol}$ Cell Biol 2005;25:7170-80.

212 Boehme KA, Kulikov R, Blattner C. p53 stabilization in response to DNA damage requires Akt/PKB and DNA-PK. Proc Natl Acad Sci U S A 2008;105:7785-90.

213 Meek DW, Hupp TR. The regulation of MDM2 by multisite phosphorylationopportunities for molecular-based intervention to target tumours? Semin Cancer Biol 2010;20:19-28.

214 Leszczynska KB, Foskolou IP, Abraham AG, et al. Hypoxia-induced p53 modulates both apoptosis and radiosensitivity via AKT. J Clin Invest 2015;125:2385-98.

215 Potiron VA, Abderrahmani R, Abderrhamani R, et al. Radiosensitization of prostate cancer cells by the dual PI3K/mTOR inhibitor BEZ235 under normoxic and hypoxic conditions. Radiother Oncol 2013:106:138-46.

216 Kuger S, Flentje M, Djuzenova CS. Simultaneous perturbation of the MAPK and the PI3K/mTOR pathways does not lead to increased radiosensitization. Radiat Oncol 2015; 10:214

217 Cox AD, Fesik SW, Kimmelman AC, et al. Drugging the undruggable RAS: Mission possible? Nat Rev Drug Discov 2014;13:828-51.

218 Ihle NT, Byers LA, Kim ES, et al. Effect of KRAS oncogene substitutions on protein behavior: implications for signaling and clinical outcome. J Nat/ Cancer Inst 2012;104:228-39.

219 Van Cutsem E, van de Velde H, Karasek P, et al. Phase III trial of gemcitabine plus tipifarnib compared with gemcitabine plus placebo in advanced pancreatic cancer. J Clin Oncol 2004;22:1430-8.

220 Kamerkar S, LeBleu VS, Sugimoto $\mathrm{H}$, et al. Exosomes facilitate therapeutic targeting of oncogenic KRAS in pancreatic cancer. Nature 2017;546:498-503.

221 Zorde Khvalevsky E, Gabai R, Rachmut IH, et al. Mutant KRAS is a druggable target for pancreatic cancer. Proc Natl Acad Sci U S A 2013:110:20723-8.

222 Singh A, Greninger P, Rhodes D, et al. A gene expression signature associated with "K-Ras addiction" reveals regulators of EMT and tumor cell survival. Cancer Cell 2009;15:489-500. 
223 Ko AH, Bekaii-Saab T, Van Ziffle J, et al. A multicenter, open-label phase ii clinical trial of combined mek plus egfr inhibition for chemotherapy-refractory advanced pancreatic adenocarcinoma. Clin Cancer Res 2016;22:61-8.

224 Infante JR, Somer BG, Park JO, et al. A randomised, double-blind, placebo-controlled trial of trametinib, an oral MEK inhibitor, in combination with gemcitabine for patients with untreated metastatic adenocarcinoma of the pancreas. Eur $\mathrm{J}$ Cancer 2014;50:2072-81.

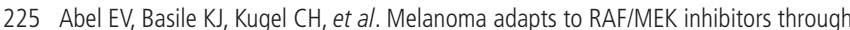
FOXD3-mediated upregulation of ERBB3. J Clin Invest 2013;123:2155-68.

226 Pettazzoni P, Viale A, Shah P, et al. Genetic events that limit the efficacy of MEK and RTK inhibitor therapies in a mouse model of KRAS-driven pancreatic cancer. Cancer Res 2015;75:1091-101.

227 Shimizu T, Tolcher AW, Papadopoulos KP, et al. The clinical effect of the dualtargeting strategy involving PI3K/AKT/mTOR and RAS/MEK/ERK pathways in patients with advanced cancer. Clin Cancer Res 2012;18:2316-25.

228 Koplev S, Longden J, Ferkinghoff-Borg J, et al. Dynamic rearrangement of cell states detected by systematic screening of sequential anticancer treatments. Cell Rep 2017;20:2784-91.

229 Miller BW, Morton JP, Pinese M, et al. Targeting the LOX/hypoxia axis reverses many of the features that make pancreatic cancer deadly: inhibition of LOX abrogates metastasis and enhances drug efficacy. EMBO Mol Med 2015;7:1063-76.

230 Olive KP, Jacobetz MA, Davidson CJ, et al. Inhibition of Hedgehog signaling enhances delivery of chemotherapy in a mouse model of pancreatic cancer. Science 2009;324:1457-61.

231 Jacobetz MA, Chan DS, Neesse A, et al. Hyaluronan impairs vascular function and drug delivery in a mouse model of pancreatic cancer. Gut 2013;62:112-20.

232 Provenzano PP, Cuevas C, Chang AE, et al. Enzymatic targeting of the stroma ablates physical barriers to treatment of pancreatic ductal adenocarcinoma. Cancer Cell 2012;21:418-29.

233 Özdemir BC, Pentcheva-Hoang T, Carstens JL, et al. Depletion of carcinomaassociated fibroblasts and fibrosis induces immunosuppression and accelerates pancreas cancer with reduced survival. Cancer Cell 2014;25:719-34.

234 Rhim AD, Oberstein PE, Thomas DH, et al. Stromal elements act to restrain, rather than support, pancreatic ductal adenocarcinoma. Cancer Cell 2014;25:735-47.

235 Vennin C, Chin VT, Warren SC, et al. Transient tissue priming via ROCK inhibition uncouples pancreatic cancer progression, sensitivity to chemotherapy, and metastasis. Sci Transl Med 2017;9:eaai8504.

236 Nobis M, McGhee EJ, Morton JP, et al. Intravital FLIM-FRET imaging reveals dasatinib-induced spatial control of src in pancreatic cancer. Cancer Res 2013;73:4674-86.

237 Sullivan R, Paré GC, Frederiksen LJ, et al. Hypoxia-induced resistance to anticancer drugs is associated with decreased senescence and requires hypoxia-inducible factor-1 activity. Mol Cancer Ther 2008;7:1961-73.

238 Wilson WR, Hay MP. Targeting hypoxia in cancer therapy. Nat Rev Cancer 2011;11:393-410.

239 Rofstad EK, Galappathi K, Mathiesen B, et al. Fluctuating and diffusion-limited hypoxia in hypoxia-induced metastasis. Clin Cancer Res 2007;13:1971-8.

240 Chang Q, Jurisica I, Do T, et al. Hypoxia predicts aggressive growth and spontaneous metastasis formation from orthotopically grown primary xenografts of human pancreatic cancer. Cancer Res 2011;71:3110-20.

241 Hardie RA, van Dam E, Cowley M, et al. Mitochondrial mutations and metabolic adaptation in pancreatic cancer. Cancer Metab 2017:5:2

242 Warburg O, Wind F, Negelein E. The metabolism of tumors in the body. J Gen Physiol 1927:8:519-30.

243 Denko NC. Hypoxia, HIF1 and glucose metabolism in the solid tumour. Nat Rev Cancer 2008;8:705-13.

244 Cohen R, Neuzillet C, Tijeras-Raballand A, et al. Targeting cancer cell metabolism in pancreatic adenocarcinoma. Oncotarget 2015;6:16832-47.

245 Maftouh M, Avan A, Sciarrillo R, et al. Synergistic interaction of novel lactate dehydrogenase inhibitors with gemcitabine against pancreatic cancer cells in hypoxia. Br J Cancer 2014:110:172-82.

246 Ying $\mathrm{H}$, Kimmelman AC, Lyssiotis CA, et al. Oncogenic Kras maintains pancreatic tumors through regulation of anabolic glucose metabolism. Cell 2012;149:656-70.

247 Shukla SK, Purohit V, Mehla K, et al. MUC1 and HIF-1alpha Signaling Crosstalk Induces Anabolic Glucose Metabolism to Impart Gemcitabine Resistance to Pancreatic Cancer. Cancer Cell 2017;32:71-87.

248 Parks SK, Cormerais Y, Durivault J, et al. Genetic disruption of the pHi-regulating proteins $\mathrm{Na}+\mathrm{H}+$ exchanger 1 (SLC9A1) and carbonic anhydrase 9 severely reduces growth of colon cancer cells. Oncotarget 2017;8:10225-37.

249 Ward C, Meehan J, Mullen P, et al. Evaluation of carbonic anhydrase IX as a therapeutic target for inhibition of breast cancer invasion and metastasis using a series of in vitro breast cancer models. Oncotarget 2015;6:24856-70.

250 Carta F, Vullo D, Osman SM, et al. Synthesis and carbonic anhydrase inhibition of a series of SLC-0111 analogs. Bioorg Med Chem 2017;25:2569-76.

251 Faes S, Planche A, Uldry E, et al. Targeting carbonic anhydrase IX improves the anticancer efficacy of mTOR inhibitors. Oncotarget 2016;7:36666-80.

252 Sun JD, Ahluwalia D, Liu Q, et al. Combination treatment with hypoxia-activated prodrug evofosfamide (TH-302) and mTOR inhibitors results in enhanced antitumor efficacy in preclinical renal cell carcinoma models. Am J Cancer Res 2015:5:2139-55

253 Brown JM. SR 4233 (tirapazamine): a new anticancer drug exploiting hypoxia in solid tumours. Br J Cancer 1993:67:1163-70.

254 Jones GD, Weinfeld M. Dual action of tirapazamine in the induction of DNA strand breaks. Cancer Res 1996;56:1584-90.

255 Rischin D, Peters LJ, O'Sullivan B, et al. Tirapazamine, cisplatin, and radiation versus cisplatin and radiation for advanced squamous cell carcinoma of the head and neck (TROG 02.02, HeadSTART): a phase III trial of the Trans-Tasman Radiation Oncology Group. J Clin Oncol 2010:28:2989-95.

256 Borad MJ, Reddy SG, Bahary N, et al. Randomized phase II trial of gemcitabine plus $\mathrm{TH}-302$ versus gemcitabine in patients with advanced pancreatic cancer. J Clin Oncol 2015:33:1475-81.

257 Guise CP, Abbattista MR, Singleton RS, et al. The bioreductive prodrug PR-104A is activated under aerobic conditions by human aldo-keto reductase 1C3. Cancer Res 2010;70:1573-84.

258 Hicks KO, Siim BG, Jaiswal JK, et al. Pharmacokinetic/pharmacodynamic modeling identifies SN30000 and SN29751 as tirapazamine analogues with improved tissue penetration and hypoxic cell killing in tumors. Clin Cancer Res 2010;16:4946-57.

259 Albertella MR, Loadman PM, Jones PH, et al. Hypoxia-selective targeting by the bioreductive prodrug AQ4N in patients with solid tumors: results of a phase I study. Clin Cancer Res 2008;14:1096-104.

260 Matsumoto S, Kishimoto S, Saito K, et al. Metabolic and physiologic imaging biomarkers of the tumor microenvironment predict treatment outcome with radiation or a hypoxia-activated prodrug in mice. Cancer Res 2018;78:3783-92.

261 O'Connor LJ, Cazares-Körner C, Saha J, et al. Design, synthesis and evaluation of molecularly targeted hypoxia-activated prodrugs. Nat Protoc 2016;11:781-94.

262 Yap TA, Yan L, Patnaik A, et al. First-in-man clinical trial of the oral pan-AKT inhibitor MK-2206 in patients with advanced solid tumors. J Clin Oncol 2011;29:4688-95.

263 Yap TA, Yan L, Patnaik A, et al. Interrogating two schedules of the AKT inhibitor MK-2206 in patients with advanced solid tumors incorporating novel pharmacodynamic and functional imaging biomarkers. Clin Cancer Res 2014;20:5672-85.

264 Molife L, Yan L, Vitfell-Rasmussen J, et al. Phase 1 trial of the oral AKT inhibitor MK2206 plus carboplatin/paclitaxel, docetaxel, or erlotinib in patients with advanced solid tumors. J Hematol Oncol 2014;7:1.

265 Chung V, McDonough S, Philip PA, et al. Effect of selumetinib and mk-2206 vs oxaliplatin and fluorouracil in patients with metastatic pancreatic cancer after prior therapy: Swog s1115 study randomized clinical trial. JAMA Oncol 2017;3:516-22.

266 Tolcher AW, Patnaik A, Papadopoulos KP, et al. Phase I study of the MEK inhibitor trametinib in combination with the AKT inhibitor afuresertib in patients with solid tumors and multiple myeloma. Cancer Chemother Pharmacol 2015;75:183-9.

267 Hong DS, Henary H, Falchook GS, et al. First-in-human study of pbi-05204, an

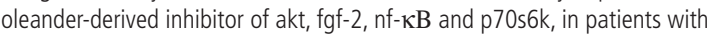
advanced solid tumors. Invest New Drugs 2014;32:1204-12.

268 Marsh RW, Rocha Lima CM, Levy DE, et al. A phase II trial of perifosine in locally advanced, unresectable, or metastatic pancreatic adenocarcinoma. Am J Clin Oncol 2007;30:26-31

269 Tolcher AW, Bendell JC, Papadopoulos KP, et al. A phase IB trial of the oral MEK inhibitor trametinib (GSK1120212) in combination with everolimus in patients with advanced solid tumors. Ann Oncol 2015;26:58-64.

270 McRee AJ, Sanoff HK, Carlson C, et al. A phase I trial of mFOLFOX6 combined with the oral PI3K inhibitor BKM120 in patients with advanced refractory solid tumors. Invest New Drugs 2015;33:1225-31.

271 Bedard PL, Tabernero J, Janku F, et al. A phase Ib dose-escalation study of the oral pan-PI3K inhibitor buparlisib (BKM120) in combination with the oral MEK1/2 inhibitor trametinib (GSK1120212) in patients with selected advanced solid tumors. Clin Cancer Res 2015:21:730-8.

272 Bowles DW, Ma WW, Senzer N, et al. A multicenter phase 1 study of PX-866 in combination with docetaxel in patients with advanced solid tumours. $\mathrm{Br} J$ Cancer 2013;109:1085-92

273 Patnaik A, Appleman LJ, Tolcher AW, et al. First-in-human phase I study of copanlisib (BAY 80-6946), an intravenous pan-class I phosphatidylinositol 3-kinase inhibitor, in patients with advanced solid tumors and non-Hodgkin's lymphomas. Ann Oncol 2016;27:1928-40.

274 Azaro A, Rodon J, Calles A, et al. A first-in-human phase I trial of LY2780301, a dua p70 S6 kinase and Akt Inhibitor, in patients with advanced or metastatic cancer. Invest New Drugs 2015;33:710-9.

275 Markman B, Tabernero J, Krop I, et al. Phase I safety, pharmacokinetic, and pharmacodynamic study of the oral phosphatidylinositol-3-kinase and mTOR inhibitor BGT226 in patients with advanced solid tumors. Ann Oncol 2012;23:2399-408.

276 Papadopoulos KP, Tabernero J, Markman B, et al. Phase I safety, pharmacokinetic, and pharmacodynamic study of SAR245409 (XL765), a novel, orally administered $\mathrm{PI3K} / \mathrm{mTOR}$ inhibitor in patients with advanced solid tumors. Clin Cancer Res 2014;20:2445-56

277 Mahadevan D, Chiorean EG, Harris WB, et al. Phase I pharmacokinetic and pharmacodynamic study of the pan-PI3K/mTORC vascular targeted pro-drug SF1126 
in patients with advanced solid tumours and B-cell malignancies. Eur J Cancer 2012;48:3319-27.

278 Wainberg ZA, Alsina M, Soares HP, et al. A Multi-Arm Phase I Study of the PI3K/ mTOR Inhibitors PF-04691502 and Gedatolisib (PF-05212384) plus Irinotecan or the MEK Inhibitor PD-0325901 in Advanced Cancer. Target Oncol 2017:12:775-85.
279 Shapiro GI, Bell-McGuinn KM, Molina JR, et al. First-in-Human Study of PF05212384 (PKI-587), a Small-Molecule, Intravenous, Dual Inhibitor of PI3K

and mTOR in Patients with Advanced Cancer. Clin Cancer Res 2015;21:1888-95.

280 Balachandran VP, Łuksza M, Zhao JN, et al. Identification of unique neoantigen qualities in long-term survivors of pancreatic cancer. Nature 2017;551:512-6. 